\title{
Experimentaluntersuchung über die Bildung von Hypochlorit und Chlorat bei der Elektrolyse von Alkalichloriden.
}

\author{
Von \\ ERrCh MüLter.
}

Mit 14 Figuren im Text.

Durch die vorangegangenen theoretischen Betrachtungen des Herrn Prof. Foerster ist im allgemeinen der Weg gekennzeichnet, den die folgende Experimentaluntersuchung einzuschlagen hat, die sich damit beschäftigt, die Vorgänge der Hypochlorit- und Chloratbildung bei der Elektrolyse wässeriger Chloralkalilösungen zu untersuchen.

Es wird dabei in erster Linie darauf ankommen, die bekannten Erscheinungen bei der Bildung dieser Verbindungen auf rein chemischem Wege durch Einwirkung von Chlor auf Alkalihydratlösungen sich zu vergegenwärtigen und festzustellen, ob diese auch bei der elektrolytischen Hypochlorit- und Chloratbildung sich wiederfinden oder nicht, ob wir gezwungen sind, neben oder an Stelle von den rein chemischen besondere Vorgänge elektrochemischer Natur anzunehmen.

In zweiter Linie war zu untersuchen, ob die sowohl in saurer wie in neutraler und alkalischer Lösung beobachtete elektrolytische Chloratbildung ihrer Natur nach ein und derselbe Vorgang ist, oder ob verschiedene, durch die wechselnden Bedingungen bald mehr bald weniger begünstigte Vorgänge hier im Spiele sind.

\section{Elektrolyse von Alkalichloridlösungen ohne Zusatz von Alkali- hydraten.}

\section{A. Ontersuchungen in neutraler Chloralkalilösung.}

Wenn man voraussetzt, dafs bei der Elektrolyse neutraler Chloralkalilösungen die Hypochlorit- und Chloratbildung im wesentlichen auf demselben Wege erfolgt, wie bei dem rein chemischen Vorgang der Einwirkung von Chlor auf Alkalihydratlösungen, so hat man folgende Schlufsfolgerungen aus dieser Annahme, welche experimentell zu prüfen sind. 
1. Chlor mufs thatsächlich dauernd in elementarem Zustande an der Anode auftreten.

2. Bei Beginn der Elektrolyse muls zuerst das Hypochlorit entstehen, als Ausgangskörper für das Chlorat; je höher seine Konzentration steigt, um so schneller muls es in Chlorat übergehen. Schliefslich muls seine Konzentration einen konstanten Wert annehmen; der Betrag, bei welchem dies der Fall ist, muls von den. Versuchsbedingungen abhängen, doch so, dafs wenn diese die Geschwindigkeit der Umwandlung in Chlorat erhöhen, der konstante Wert der Hypochloritkonzentration sinkt.

3. Die Chloratbildung erfolgt durch freie unterchlorige Säure, welch letztere durch Entladung von $\overline{\mathrm{ClO}}$-Ionen an der Anode entsteht. Da diese nur in geringer Menge gegenüber $\overline{\mathrm{Cl}}-\mathrm{I}$ (onen auftreten, so müssen sie leichter entladbar sein als letztere.

Es soll zunächst der zweite dieser Punkte an der Hand von Versuchen erläutert werden. Der zeitliche Verlauf der Hypochloritund Chloratbildung bei der Alkalichloridelektrolyse ist bisher noch nicht genügend eingehend untersucht worden.

Zur Elektrolyse wurde stets Chlornatrium gewählt, um einem Auskrystallisieren von Chlorat; wie es bei Verwendung von Chlorkalium zu befürchten ist, vorzubeugen, wodurch eine einfache Deutung der Ergebnisse hätte beeinträchtigt werden können.

Die Mengen des gebildeten Hypochlorits und Chlorats wurden in der Weise ermittelt, dals in bestimmten Zeitabschnitten je $2 \mathrm{ccm}$ Lösung dem Elektrolyten entnommen und analysiert wurden; sie sind angegeben, in dem ihnen entsprechenden Betrage an aktivem Sauerstoff. Was die bei der Bestimmung befolgte analytische Methode anbetrifft, so sei auf die Arbeit von Förster und JonRE ${ }^{1}$ verwiesen.

Um diese Versuche an diejenigen von OETTEL ${ }^{2}$ anzuschliefsen, wurden sie gleichzeitig gasanalytisch verfolgt. Eine Beschreibung der Methode kann - da sie wohl als allgemein bekannt vorausgesetzt werden darf - fortgelassen werden. Die jeweilige Stromstärke wurde in allen Fällen durch ein Ampermeter beobachtet, die für einen Versuch aufgewandte gesamte Strommenge aus der in einem Kupfervoltameter niedergeschlagenen Menge Kupfer berechnet, und die an den Elektroden herrschende Spannung durch ein Voltmeter bestimmt. Die genannten Mefsinstrumente waren

1 Journ. pr. Chem. (1899) $59,53 \mathrm{ff}$.

2 Zeitschr. Elelitrochem. 1895, Heft 11 und 15 . 
mit der Zersetzungszelle und einem Knallgasvoltameter in den Stromkreis eingeschaltet.

Für die Versuche 1-3, 5, 6, 15-21 diente zur Aufnahme des Elektrolyten ein etwa $550 \mathrm{ccm}$ fassendes Glasgefäfs, das durch einen Gummistopfen luftdicht verschliefsbar war. Der letztere hatte 5 Durchbohrungen. In die eine war ein Gasableitungsrohr, in die zweite ein verschlielsbares Rohr zur Entnahme von Flüssigkeitsproben, in die anderen drei die Elektroden, deren Zuleitungsdrähte in Glasröhren eingeschmolzen waren, eingepalst. Die Elektroden bestanden aus Platin und waren als rechteckige Bleche vertikal und parallel zu einander mit $1.5 \mathrm{~cm}$ Entfernung aufgehängt. In der Mitte befand sich die Anode mit einer beiderseitigen Oberfläche von $58 \mathrm{qcm}$, zu beiden Seiten derselben die kleineren Kathoden, jede mit einer einseitig wirksamen Oberfläche von $12 \mathrm{qcm}$.

Die Stromstärke betrug 4.5 Ampère.

Versuch 1.

Temperatur $8-12^{\circ} \mathrm{C}$.

Die Lösung $(500 \mathrm{ccm})$ enthielt $30 \mathrm{~g} \mathrm{NaCl}$ in $100 \mathrm{~cm}$.

$D_{K}=0.18 \mathrm{Amp} / \mathrm{qem} . D_{u}=0.075 \mathrm{Amp} . / \mathrm{qem}$.

Spannung 4.6-4.7 Volt.

\begin{tabular}{|c|c|c|c|c|c|}
\hline \multirow{2}{*}{$\begin{array}{l}\text { Versuchs- } \\
\text { dauer } \\
\text { Stunden }{ }^{1}\end{array}$} & \multirow{2}{*}{$\begin{array}{c}\text { Strom- } \\
\text { ausbeute } \\
\%\end{array}$} & \multirow{2}{*}{$\begin{array}{c}\text { Reduktion } \\
0 / 0\end{array}$} & \multirow{2}{*}{$\begin{array}{c}\text { Sauerstoff- } \\
\text { entwickelung } \\
0 / 0\end{array}$} & \multicolumn{2}{|c|}{$\begin{array}{c}\text { Aktiver Sauerstoff } \\
\text { in } 500 \mathrm{ccm} \\
\text { als }\end{array}$} \\
\hline & & & & $\begin{array}{c}\text { Hypochlorit } \\
\mathrm{g}\end{array}$ & $\begin{array}{c}\text { Chlorat } \\
\mathrm{g}\end{array}$ \\
\hline $1 / 4$ & 86.0 & 8.8 & 5.2 & 0.17 & 0.06 \\
\hline $1 / 2$ & 82.6 & 13.4 & 4.0 & 0.39 & 0.08 \\
\hline $3 / 4$ & 77.5 & 18.4 & 4.1 & 0.73 & - \\
\hline $1^{\prime 4}$ & 73.2 & 23.1 & 3.7 & 0.91 & 0.08 \\
\hline $1^{1 / 2}$ & 64.6 & 30.7 & 4.7 & 1.43 & 0.07 \\
\hline 2 & 54.8 & 36.4 & 8.8 & 1.58 & 0.23 \\
\hline 3 & 46.7 & 44.1 & 9.2 & 2.15 & 0.40 \\
\hline 4 & 36.7 & 51.2 & 12.1 & 2.62 & 0.74 \\
\hline 5 & 36.4 & 49.0 & 13.7 & 2.76 & - \\
\hline 6 & 34.7 & 51.1 & 14.2 & 2.76 & 1.53 \\
\hline 7 & 32.3 & 51.4 & 16.3 & 2.76 & 2.11 \\
\hline 8 & 32.3 & 51.3 & 16.4 & 2.86 & 2.32 \\
\hline
\end{tabular}

Im Voltameter niedergeschlagen $43.0 \mathrm{~g} \mathrm{Cu}=10.8 \mathrm{~g}$ Sauerstoff. Die Lauge enthielt wirksamen Sauerstoff $5.18 \mathrm{~g}=\mathbf{4 7 . 0} \%$ Stromausbeute.

1 Nach Ablauf der hier angeführten Zeit wurde mit dem Auffangen der Gase begonnen. Die Entnahme der Lösungsproben erfolgte in allen Fällen direkt im Anschinfs an die Gasentnahme. Die Resultate für die Mengen Hypochlorit- und Chloratsauerstoff bezieben sich also strenggenommen auf einen etwas späteren Zustand der Lösung. 


\section{Versuch 2.}

Temperatur $50^{\circ} \mathrm{C}$.

Die Lösung (500 ccm) enthielt $30 \mathrm{~g} \mathrm{NaCl}$ in $100 \mathrm{ccm}$. $D_{K}=0.18$ Amp. $/ \mathrm{qcm} . D_{a}=0.075 \mathrm{Amp} . / \mathrm{qcm}$.

Spannung 3.9-4.0 Volt.

\begin{tabular}{|c|c|c|c|c|c|}
\hline \multirow{2}{*}{$\begin{array}{l}\text { Versuchs- } \\
\text { dauer } \\
\text { Stunden }\end{array}$} & \multirow{2}{*}{$\begin{array}{c}\text { Strom- } \\
\text { ausbeute } \\
\% \\
\%\end{array}$} & \multirow{2}{*}{$\begin{array}{c}\text { Reduktion } \\
\%\end{array}$} & \multirow{2}{*}{$\begin{array}{c}\text { Sauerstoff- } \\
\text { entwickelung } \\
\% \\
\end{array}$} & \multicolumn{2}{|c|}{$\begin{array}{c}\text { Aktiver Sauerstoff } \\
\text { in } 500 \mathrm{cem} \\
\text { als }\end{array}$} \\
\hline & & & & $\begin{array}{c}\text { Hypochlorit } \\
\mathrm{g}\end{array}$ & $\begin{array}{c}\text { Chlorat } \\
\text { g }\end{array}$ \\
\hline $1 / 4$ & 75.9 & 20.5 & 3.6 & 0.41 & 0.08 \\
\hline $1 / 2$ & 63.3 & 32.3 & 4.4 & - & - \\
\hline $3 / 4$ & 58.1 & 36.3 & 5.6 & 0.79 & 0.14 \\
\hline 1 & 52.3 & 41.3 & 6.4 & - & - \\
\hline $1^{1 / 4}$ & 47.6 & 44.9 & 7.5 & 0.97 & 0.26 \\
\hline $11 / 2$ & 41.9 & 48.6 & 9.5 & 1.04 & 0.34 \\
\hline 2 & 35.5 & 53.3 & 11.2 & 1.11 & 0.55 \\
\hline $2^{1 / 8}$ & 35.0 & 53.5 & 11.5 & 1.15 & 0.77 \\
\hline 3 & 33.4 & 54.7 & 11.9 & 1.15 & 0.95 \\
\hline $3^{1 / 2}$ & 33.1 & 54.8 & 12.1 & 1.14 & 1.18 \\
\hline 4 & 33.1 & 54.5 & 12.4 & 1.15 & 1.42 \\
\hline 18 & 30.8 & 56.7 & 12.5 & 1.15 & 7.63 \\
\hline 19 & 32.6 & 54.8 & 12.8 & - & - \\
\hline 21 & 32.8 & 54.8 & 12.8 & 1.15 & 9.26 \\
\hline
\end{tabular}

Im Voltameter niedergeschlagen $112 \mathrm{~g} \mathrm{Cu}=28.2 \mathrm{~g}$ Sauerstoff. Die Lauge enthielt wirksamen Sauerstoff $10.4 \mathrm{~g}=36.8 \%$ Stromausbeute.

Um eine bessere Übersicht über die durch diese beiden Versuche gewonnenen Resultate zu gewinnen, wurden dieselben in je ein Koordinatensystem eingezeichnet.

Auf der Abscissenachse ist die Versuchsdauer in Stunden, auf der Ordinate die dem gebildeten Hypochlorit und Chlorat entsprechende Menge aktiven Sauerstoffes in Decigrammen resp. die zur Reduktion und zur Sauerstoffentwickelung verbrauchten Anteile der Stromarbeit in Prozenten aufgetragen.

Diese Versuche bestätigen vollständig die oben unter 2 ausgesprochene Erwartung, indem sie zeigen, dals die Kurve für Hypochlorit allmählich bis zu einem Punkte ansteigt, von dem ab sie parallel zur Abscissenachse verläuft und der in der Kälte ungefähr doppelt so hoch liegt wie in der Wärme. Dieser Punkt ist aber auch charakteristisch für sämtliche anderen Kurven. Die Chloratkurve, welche bis dahin nach unten gekrümmt verlief, nimmt von diesem Punkte an eine geradlinig steigende Richtung und die Kurven für Reduktion und Sauerstoffentwickelung sind mit der des Hypochlorits 
fast genau in ihrem Verlauf identisch. Der charakteristische Punkt ist in der Kälte nach 4, in der Wärme nach 2 Stunden erreicht.

Neutrale Lösungen von $\mathrm{NaCl} .10$ bis $18^{\circ} \mathrm{C}$.

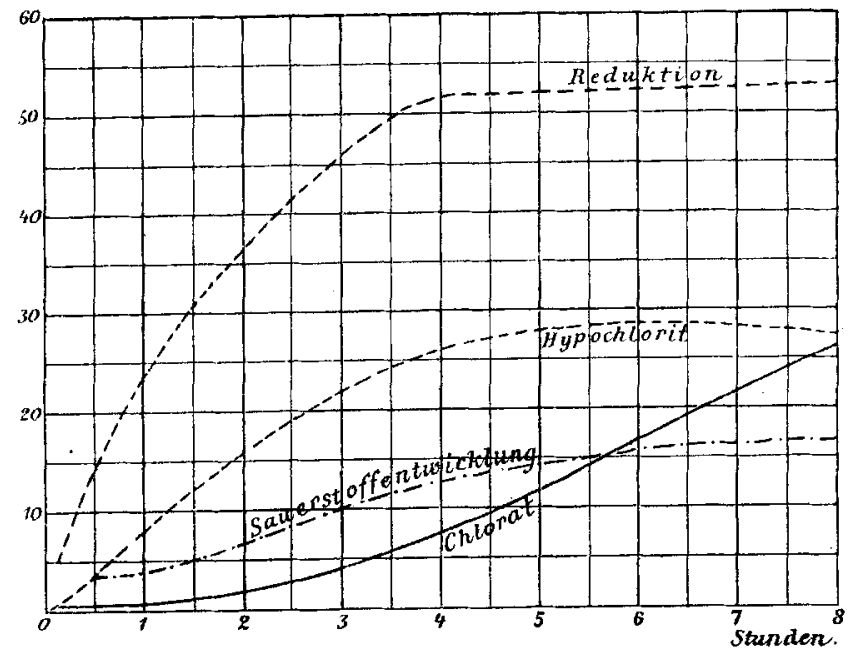

Fig. 1.

Neutrale Lösung von $\mathrm{NaCl} .50^{\circ} \mathrm{C}$.

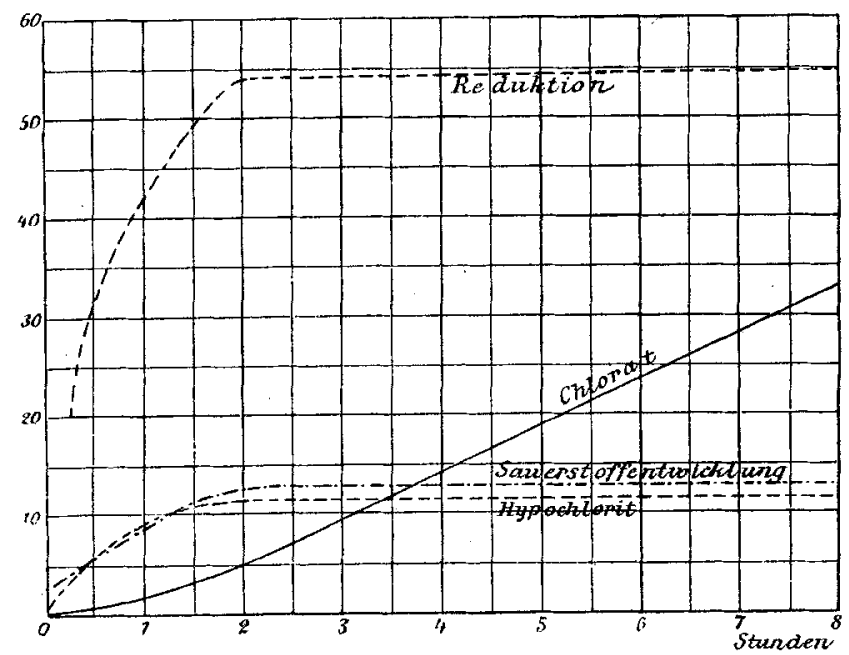

Fig. 2. 
$\mathrm{H}_{\mathrm{ABER}}{ }^{1}$ erklärt die elektrolytische Bildung des Chlorats in der Weise, dals er annimmt, $\overline{\mathrm{Cl}}$ - und $\overline{\mathrm{O}} \mathrm{H}-\mathrm{I}$-nen vereinigen sich nach ihrer Entladung zu $\mathrm{HClO}_{3}$. Die für diese Reaktion nötigen $\overline{\mathrm{O}} \mathrm{H}$ ionen sollen dadurch entstehen, dafs der Elektrolyt durch das zu Beginn der Elektrolyse entweichende Chlor alkalisch wird und dafs das zunächst entstehende Hypochlorit hydrolytisch gespalten ist.

Die zu Anfang entweichende Chlormenge ist nun aber sehr gering.

Bei einem dem Versuche I analogen Versuche entwich Chlor:

$$
\begin{aligned}
& \text { In den ersten } 2 \text { Minuten } 0.0134 \mathrm{~g} \text {, } \\
& \text { " " folgenden } 3 \quad \text {., } 0.0128 \mathrm{~g} \text {, } \\
& \text { " " } \quad 3 \quad, \quad 0.0021 \mathrm{~g} \text {, }
\end{aligned}
$$

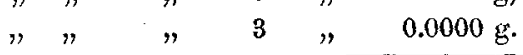

$$
\begin{aligned}
& \text { Sa. } 0.0283 \mathrm{~g} \text { Chlor. }
\end{aligned}
$$

Die durch den Fortgang des Chlors entstandene Menge freien Alkalis berechnet sich danach zu $0.0319 \mathrm{~g} \mathrm{NaOH}$ für $500 \mathrm{ccm}$ oder der Elektrolyt ist $0.0064 \%$ alkalisch geworden. Dieser in anderen Fällen noch erheblich niedriger gefundene Betrag der Alkalität hat zwar offenbar eine Vermehrung der Hydroxylionen im Elektrolyten zur Folge, aber während bereits nach 8 Minuten kein Chlor mehr aus der Zelle entweicht, während also der Höhepunkt der Alkalität weit früher erreicht ist, findet in der Kälte erst nach 11/2 Stunden eine merkliche Chloratbildung statt.

Danach ist der erste Teil der HaBEI'schen Erklärung nicht zutreffend; es bliebe also nur noch die Annahme, dafs die hydrolytisch durch das Hypochlorit abgespaltenen $\overline{\mathrm{O}} \mathrm{H}-\mathrm{Ionen}$ in solcher Menge in der Lösung auftreten, dals sie mit gleichzeitig entladenen Chlorionen zu Chlorat zusammentreten könnten. Es sei hervorgehoben, dafs diese Deutung ebenfalls mit den bisherigen Versuchen im Einklang stehen würde.

Um sie zu prüfen, wurde der folgende Versuch angestellt. Die Zusammensetzung des Elektrolyten war bei denselben nur insofern von derjenigen in Versuch I verschieden, als gleich zu Beginn so viel freies Alkali hinzugefügt wurde, als bei Versuch I hätte entstehen müssen, wenn $10 \%$ des dort entstandenen Hypochlorits hydrolytisch gespalten gewesen wären.

${ }^{1} \mathrm{Z}$. anorg. Chem. 16, 333 und 334. 
Versuch 3.

Temperatur $8-12^{\circ} \mathrm{C}$.

Die Lösung (500 ccm) enthielt $25 \mathrm{~g} \mathrm{NaCl}$ in $100 \mathrm{ccm}+0.1 \% \mathrm{NaOH}$.

$D_{a}=0.075 \mathrm{Amp} . / \mathrm{qem} . D_{K}=0.18 \mathrm{Amp} . / \mathrm{qcm}$.

Spannung 4.6 Volt. Stromstärke 4.5 Amp.

\begin{tabular}{c|c|c}
\hline $\begin{array}{c}\text { Versuchs- } \\
\text { dauer } \\
\text { Stunden }\end{array}$ & $\begin{array}{c}\text { Hypochlorit, } \\
\text { Sauerstoff } \\
\mathrm{g}\end{array}$ & $\begin{array}{c}\text { Chlorat, } \\
\text { Sauerstoff } \\
\mathrm{g}\end{array}$ \\
\hline \hline $1 / 4$ & 0.384 & 0.000 \\
$1 / 2$ & 0.571 & 0.019 \\
$3 / 4$ & 0.802 & 0.047 \\
1 & 1.002 & 0.168 \\
$11 / 4$ & 1.187 & 0.170 \\
$11 / 2$ & 1.362 & 0.184 \\
2 & 1.550 & 0.237 \\
4 & 1.638 & 1.296 \\
5 & 1650 & 1.606 \\
6 & 1.662 & 2.069 \\
7 & 1.623 & 2.509
\end{tabular}

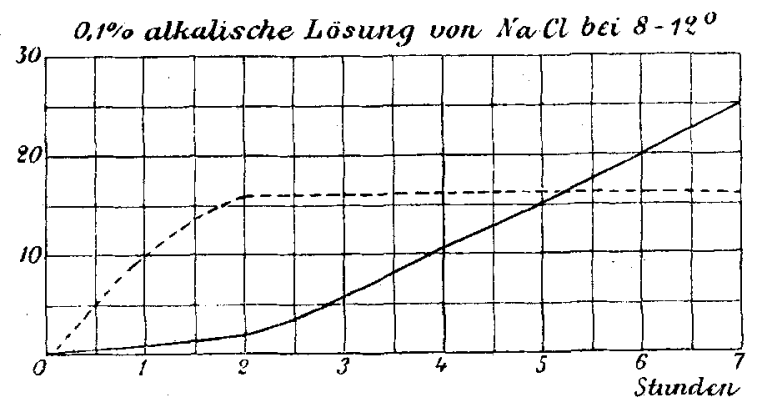

Fig. 3.

Wie man sieht, liegen hier die Verhältnisse wenigstens insofern nicht wesentlich anders wie in neutralen Lösungen, als in den ersten Stunden keine nennenswerte Chloratbildung statt hat. Wollte man daher die zweite der von HABER in Betracht gezogenen Möglichkeiten als bindend erachten, so mülste man annehmen, dafs weit uber $10 \%$ des Hypochlorits hydrolytisch gespalten sei, und das trifft nach einer von BREDig ${ }^{1}$ gemachten Mitteilung nicht zu.

${ }_{1}$ Zeitschr. Elektrochem. 4, 1, 13. 
Beweist das Entweichen von Chlor zu Beginn der Elektrolyse schon, dafs Chlor in elementarem Zustande an der Anode auftreten mufs, so lälst sich noch ein weiteres Argument erbringen, dals dies auch im weiteren Verlauf der Elektrolyse der Fall ist. Giebt man nämlich eine neutrale Chlornatriumlösung in eine Platinschale, die man zugleich als Anode benutzt und in eine Kältemischung setzt, und elektrolysiert man unter Verwendung eines gekühlten Platintiegels als Kathode, so kann man folgendes beobachten. An der Wandung der Schale lälst sich eine gelblich-grüne Belegung erkennen, und mit Fortschreiten dieser Erscheinung steigt die Spannung. Kratzt man mit einem Glasstabe an dem Boden der Schale, so steigen ganze Schollen einer Krystallmasse an das Flüssigkeitsniveau, indem die Spannung gleichzeitig wieder sinkt.

Diese Krystallkrusten verschwinden an der Oberfläche unter starkem Geruch nach Chlor und geben sich als Chlorhydrat zu erkennen.

Selbst bei einem Zusatz von Alkali bis zu 0.3 v. H. kann man diese Bildung von Chlorhydrat beobachten, und es ist dadurch nicht nur ganz einwandfrei erwiesen, dals Chlor in elementarem Zustande an der Anode auftritt, sondern gleichzeitig ersieht man daraus, dafs dasselbe dicht an der positiven Elektrode im Überschufs eine Zeit lang verweilt; da aber Chlor aus Hypochlorit unterchlorige Säure in Freiheit setzt, so liefert dieser Versuch gleichzeitig den Beweis, dals die Annahme einer Schicht freier unterchloriger Säure an der Anode gerechtfertigt ist.

Nach der für diese Untersuchungen leitenden Ansicht entsteht die genannte Säure aber auch dadurch, dal's ClO-Ionen an der Anode entladen werden und unter Sauerstoffentwickelung $\mathrm{HClO}$ bilden. Es gelang mir, für diese Auffassung eine wertvolle Stütze zu finden durch Verfolgung der anodischen Vorgänge bei der Elektrolyse einer Hypochloritlösung.

Wenn bei der Elektrolyse einer wässerigen Lösung von unterchlorigsaurem Natron die nach Beendigung gefundene Menge Chloratsauerstoff gröfser ist, als einer eventuellen Zunahme des Gesamtsauerstoffes entspricht, so mufs Hypochlorit sekundär in Chlorat verwandelt worden sein. Unter den herrschenden Temperaturverhältnissen kann dies aber nicht anders als durch Vermittelung von freier unterchloriger Säure geschehen. Eine sekundäre Bildung von Chlorat würde also eine Bestätigung der obigen Annahme sein. 
Eine Lösung von Hypochlorit, wie man sie für gewöhnlich durch Finleiten von Chlor in Natronlauge erhält, konnte hier keine Verwendung finden, da sie ja für ein Mol. NaClO stets ein Mol. $\mathrm{NaCl}$ enthält, und da es hier vor allen Dingen darauf ankam, eine möglichst von $\overline{\mathrm{Cl}}$-Ionen freie Lösung zu haben.

Es mulste deshalb der umständlichere Weg eingeschlagen werden, die Hypochloritlösung durch Neutralisation einer nach BALARD dargestellten Lösung von freier unterchloriger Säure, die durch einen Luftstrom ihres Chlorgehaltes entledigt wurde, mit der berechneten Menge Natronlauge herzustellen. Die letztere wurde, um sie völlig chlorfrei zu bekommen, durch Eintragen von Natrium in Wasser erhalten.

Trotz aller Vorsicht gelang es nicht, jede Chloratbildung und damit verbundene Entstehung von Chlorid auszuschliefsen. Dieselbe war jedoch sehr gering und beeinträchtigte, wie sich zeigte, die Ergebnisse nicht.

$50 \mathrm{ccm}$ einer solchen Lösung, die pro $100 \mathrm{ccm} 1.3422 \mathrm{~g}$ Hypochlorit- und $0.4226 \mathrm{~g}$ Chloratsauerstoff enthielt, wurden der Elektro-

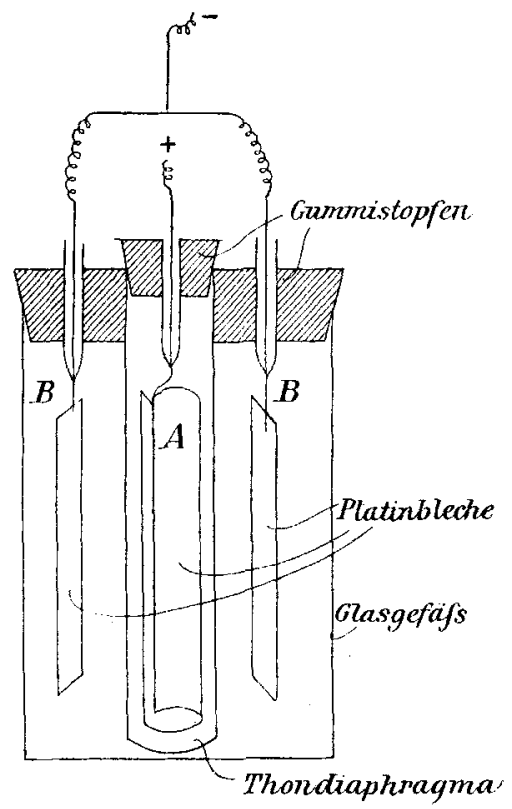

Fig. 4.

lyse in dem in Fig. 4 abgebildeten Apparat unterworfen. Die Anordnung des Versuches geht aus der Zeichnung hervor. 
A, der Anodenraum, bestand aus einem 'Thoncylinder aus Pokall'scher Masse. Er falste ca. $60 \mathrm{ccm}$ Flüssigkeit und worde mit der zu elektrolysierenden Lösung von Hypochlorit beschickt. Ein Diaphragma wurde angewandt, um einen Verlust an Hypochlorit durch Reduktion zu vermeiden.

$B$, ein Glasgefäls, falste ungefähr $550 \mathrm{ccm}$ Flüssigkeit und wurde mit $1 \%$ iger chlorfreier Natronlauge ziemlich angefüllt. Die Anode bestand aus einem Platinmantel von $20 \mathrm{qcm}$ einseitig wirksamer Oberfläche. Die Kathoden bildeten 2 Platinbleche von je $10 \mathrm{qcm}$ einseitig wirksamer Oberfläche. In den Gummistopfen waren noch aufserdem Öffnungen für Gasentnahme und Thermometer vorhanden, die in der Figur nicht gezeichnet sind.

Aus den gasanalytischen Resultaten konnte kein klares Bild gewonnen werden. Wenn im Anfang nämlich die Niveaus in $A$ und $B$ gleich hoch standen, so trat die schon oft beobachtete Erscheinung auf, dafs während der Elektrolyse die Flüssigkeit von $A$ nach $B$ gedrückt wurde.

Es konnte aus diesem Grunde nur Rücksicht genommen werden auf die vor und nach der Elektrolyse gefundenen Hypochlorit-, Chlorat- und Gesamtsauerstoffmengen. Dieselben wurden nach beendigtem Versuch in der zu 1 Liter aufgefüllten Mischung der Anodenund Kathodenlauge bestimmt. Der Stromverbrauch wurde durch ein Kupfervoltameter gemessen.

Die Stromstärke betrug $1 \mathrm{Amp}$.

\section{Versuch 4.}

Temperatur $15-18^{\circ} \mathrm{C}$.

$D_{K}=D_{a}=0.05 \mathrm{Amp} \cdot 1 \mathrm{~cm}$.

Spannung 5.5 Volt. Dauer der Elektrolyse ca. 50 Min.

\begin{tabular}{c|c|c|c}
\hline \hline $\begin{array}{c}\text { Aktiver } \\
\text { Sauerstoff als }\end{array}$ & $\begin{array}{c}\text { Vor der } \\
\text { Elektrolyse } \\
g\end{array}$ & $\begin{array}{c}\text { Nach der } \\
\text { Elektrolyse } \\
\mathrm{g}\end{array}$ & Differenz \\
\hline \hline Hypochlorit & 0.6710 & 0.3010 & 8 \\
Chlorat & 0.2114 & 0.6645 & 0.3700 \\
\hline \multicolumn{1}{c|}{ Gesamt } & 0.8824 & 0.9655 & 0.0831
\end{tabular}

Im Voltameter niedergeschlagen $0.995 \mathrm{~g} \mathrm{Cu}=0.251 \mathrm{~g}$ Sauerstoff $=33.1 \%$ Stromausbeute an hinzugekommenem aktiven Sauerstoff. 
Die Zunahme des Gesamtsauerstoffes von $0.0831 \mathrm{~g}$ bedingt im Sinne der Gleichung $\overline{\mathrm{ClO}}+2 \mathrm{O}=\overline{\mathrm{ClO}}_{3}$ eine Abnahme des Hypochloritsauerstoffes von $0.0416 \mathrm{~g}$; folglich sind verschwunden:

durch direkte Oxydation,

$$
0.0416 \mathrm{~g} \text { Hypochloritsauerstoff oder } 11.2 \%
$$

$0.3284 \mathrm{~g}$ oder $88.8 \%$

durch sekundäre Umwandlung.

In der Kathodenlauge konnte nach beendigtem Versuche ein Gehalt an Hypochlorit kaum nachgewiesen werden, so dafs ein Verlust durch Reduktion zu vernachlässigen ist.

Dieser Versuch lehrt also, dafs thatsächlich die Chloratbildung im wesentlichen nicht durch anodische Oxydation erfolgt, sondern aus dem Hypochloritsauerstoff hervorgeht. Da ein. derartiger Übergang auf rein chemischem Wege stets durch Oxydation mittels unterchloriger Säure erfolgt, so mufs auch hier diese entstanden sein, und das kann nur der Fall sein durch Entladung von ClO-Ionen.

Es sei hier auf die fundamentale Bedeutung dieses Versuches für die Untersuchungen über die elektrolytische Chloratbildung besonders aufmerksam gemacht, indem er in Übereinstimmung mit dem beobachteten Auftreten von festern Chlorbydrat an gekühlter Anode uns nicht im Zweifel darüber lälst, dafs wir es dicht an der Anode mit einer sauren Lösung zu thun haben.

Sehr interessant ist es, dals in geringem Umfange auch eine Vermehrung des aktiven Sauerstoffes durch direkte anodische Oxydation stattfindet. Auf diese soll später eingegangen werden.

Der eben erwähnte Versuch weist noch weiter ganz unzweideutig darauf hin, dafs ClO-Ionen leichter entladbar sind als C̄-Ionen.

Da nämlich bei demselben eine Reaktion im Sinne der Gleichung $\mathrm{NaClO}+2 \mathrm{HClO}=\mathrm{NaClO}_{3}+2 \mathrm{HCl}$ vor sich geht, so sind stets $\overline{\mathrm{ClO}}-$ und $\overline{\mathrm{Cl}}$-Ionen gleichzeitig in Lösung und es mülste Chlor entweichen, wenn es neben $\overrightarrow{\mathrm{Cl} O}$ entladen würde. Dies scheint jedoch erst stattzufinden, wenn die Konzentration der Cl-Ionen eine bestimmte Höhe erreicht und die $\overline{\mathrm{ClO}}$-Ionen entsprechend abgenommen haben. Denn Chlorgeruch trat erst nach ca. 50 Minuten auf, so dafs der Versuch unterbrochen werden mulste.

Wenn man in Erwägung zieht, dafs für 3 Atome verschwundenen Hypochloritsauerstoffes 2 Mol. Salzsäure entstehen, so kann man sich aus den obigen Versuchsdaten das Konzentrationsverhältnis von Hypochlorit zu Chlorid in der Lösung in dem Zeitpunkte, bei welchem die Chlorentwickelung eintritt, zu ungefäbr ${ }^{46} / 56$ berechnen. 
Freilich kann die Entstehung von freiem Chlor auch darauf zurückgeführt werden, dafs wie stets, wenn wenig Hypochlorit zugegen ist, die Salzsäure mit der unterchlorigen Säure im Sinne der Gleichung $\mathrm{HClO}+\mathrm{HCl}=\mathrm{H}_{2} \mathrm{O}+\mathrm{Cl}_{2}$ reagiert.

Diese Ergebnisse stützen gleichzeitig die von Fogr und OETTEL gemachte Annahme, die Sauerstoffentwickelung bei der Elektrolyse neutraler Chloridlösungen entstamme dem Hypochlorit.

Damit finden denn auch die in Figg. 1 u. 2 gezeichneten Kurven ihre vollständige Deutung. Die Kurve für Sauerstoffentwickelung steigt so lange an, wie diejenige für Hypochlorit, und wenn dessen Konzentration konstant geworden, ist es auch der prozentische Betrag der Sauerstoffentwickelung. Es besteht also zwischen dem Auftreten von Hypochlorit und der Sauerstoffentwickelung vollständige Parallelität ganz ebenso, wie es hinsichtlich der Reduktion ist und sein mufs, da an Platinkathoden das Hypochlorit allein von allen Stoffen in der Lösung reduzierbar ist. Dafs die Sauerstoffentwickelung in der Wärme einen verhältnismälsig hohen Wert besitzt gegenüber der stark verminderten Hypochloritkonzentration, kann seinen Grund einmal darin haben, dafs für sie die Hypochloritkonzentration an der Anode malsgebend ist, welche von der der Gesamtlösung um so mehr verschieden erscheint, je schneller der Übergang von Hypochlorit in Chlorat erfolgt. Dann aber entweicht, wie weiter unten noch näher zu erörtern sein wird, in der Wärme der Sauerstoff, der in der Kälte zur direkten Oxydation verwendet wird.

Aus der Erkenntnis heraus, dals die Entwickelung von Sauerstoff dem Hypochlorit entstammt, erwächst unmittelbar die Folgerung, dafs die Sauerstoffentwickelung wachsen muls, wenn man unter sonst gleichbleibenden Verhältnissen die Reduktion, durch die der Anhäufung von Hypochlorit im Elektrolyten Abbruch gethan wird, vermindert, da dann die Konzentration des Hypochlorits und damit auch der Anteil der $\overline{\mathrm{ClO}}$-Ionenentladung an den anodischen Vorgängen steigt.

Ein solches Mittel, die Reduktion beinahe zu beseitigen, bietet sich dar, wie ich das gezeigt habe, wenn man dem Elektrolyten ein wenig Chromat zusetzt. ${ }^{3}$

Wie man aus den folgenden Versuchen ersieht, erreicht dann in der That die Sauerstoffentwickelung das doppelte der früher bei Versuch 1 und 2 beobachteten Werte.

\footnotetext{
1 Zeitschr. Elektrochem. 5, Nr. 41.
} 


\section{Versuch $5^{1}$}

Temperatur $8-12^{\circ} \mathrm{C}$.

Die Flüssigkeit $(500 \mathrm{ccm})$ enthielt $30 \mathrm{~g} \mathrm{NaCl}$ in $100 \mathrm{ecm}+0.9 \mathrm{~K}_{\mathbf{2}} \mathrm{CrO}_{4}$. $D_{K}=0.18 \mathrm{Amp} \cdot / \mathrm{qcm} . D_{a}=0.075 \mathrm{Amp} \cdot / \mathrm{qcm}$.

Spannung $4.9 \rightarrow 5.4$ Volt.

\begin{tabular}{c|c|c|c|c}
\hline $\begin{array}{c}\text { Versuchs- } \\
\text { dauer } \\
\text { Stunden }\end{array}$ & $\begin{array}{c}\text { Strom- } \\
\text { ausbeute } \\
\%\end{array}$ & $\begin{array}{c}\text { Reduktion } \\
\%\end{array}$ & $\begin{array}{c}\text { Sauerstoff- } \\
\text { entwickelung } \\
\%\end{array}$ & $\begin{array}{c}\text { Aktiver } \\
\text { Sauerstoff als } \\
\text { Hypochlorit } \\
\text { gyn 500 ecm }\end{array}$ \\
\hline \hline $1 / 4$ & 89.1 & 4.7 & 6.2 & - \\
$1 / 2$ & 96.0 & 1.6 & 2.4 & 0.53 \\
1 & 94.7 & 1.3 & 4.0 & 1.07 \\
$11 / 2$ & - & 0.9 & - & 1.5 \\
2 & 91.3 & 0.7 & 8.0 & 2.18 \\
4 & 68.0 & 0.1 & 32.0 & 2.94 \\
6 & 65.3 & 1.6 & 33.1 & 2.94
\end{tabular}

Im Voltameter niedergeschlagen $31.11 \mathrm{~g} \mathrm{Cu}=7.851 \mathrm{~g}$ Sauerstoff. Die Lauge enthielt wirksamen Sauerstoff $6.0423 \mathrm{~g}=76.9 \%$ Stromausbeute.

\section{Versuch 6.}

Temperatur $42-50^{\circ} \mathrm{C}$.

Die Flüssigkeit $\left(500 \mathrm{ccm}\right.$ ) enthielt $30 \mathrm{~g} \mathrm{NaCl}$ in $100 \mathrm{~cm} .+0.9 \mathrm{~g} \mathrm{~K}_{2} \mathrm{CrO}_{4}$. $D_{K}=0.18 \mathrm{Amp} . / \mathrm{qcm} . D_{a}=0.075 \mathrm{Amp} . / \mathrm{qcm}$.

Spannung 4.1-4.7 Volt.

\begin{tabular}{c|c|c|c|c}
\hline $\begin{array}{c}\text { Versuchs- } \\
\text { dauer } \\
\text { Stunden }\end{array}$ & $\begin{array}{c}\text { Strom- } \\
\text { ausbeute } \\
\%\end{array}$ & $\begin{array}{c}\text { Reduktion } \\
\%\end{array}$ & $\begin{array}{c}\text { Sauerstoff- } \\
\text { entwickelung } \\
\%\end{array}$ & $\begin{array}{c}\text { Aktiver } \\
\text { Sauerstoff als } \\
\text { Hypochlorit } \\
\text { g in 500 ccm }\end{array}$ \\
\hline \hline & 83.5 & 3.8 & 12.7 & 0.89 \\
2 & 77.6 & 2.4 & 20.0 & 1.54 \\
3 & 69.5 & 0.8 & 29.7 & 1.68 \\
4 & 71.6 & 2.1 & 26.3 & - \\
5 & 70.5 & 1.1 & 28.4 & - \\
6 & - & 0.8 & - & 1.86 \\
\hline
\end{tabular}

Im Voltametor niedergeschlagen $34.45 \mathrm{~g} \mathrm{Cu}=8.694 \mathrm{~g}$ Sauerstoff. Die Lauge enthielt wirksamen Sauerstoff $6.4451 \mathrm{~g}=74.1 \%$ Stromausbeute.

Wenn es also im allgemeinen für die Umwandlung von Hypochlorit in Chlorat günstig erscheint, dafs an der Anode viel $\overline{\mathrm{ClO}}$ Ionen entladen werden, so thun diese Versuche dar, dafs auch hier

1 Apparat wie bei Versuch 2. 
eine Grenze besteht. Bei der verhältnismälsig leichten Entladbarkeit der $\overline{\mathrm{ClO}}$-Ionen wird bei einer immer höher steigenden Hypochloritkonzentration die Entladung von Cl-Tonen immer mehr in den Hintergrund treten.

Ganz dieselben Betrachtungen lassen sich anstellen bei einer Erhöhung der kathodischen Stromdichte. Auch hier wird die Reduktion vermindert und es muls - gleiche anodische Stromdichte vorausgesetzt - die Sauerstoffentwickelung dementsprechend wachsen. Diese Verhältnisse finden sich bereits im theoretischen Teil an der Hand der OETTEL'schen Versuche abgehandelt.

Es hat sich somit gezeigt, dafs die mitgeteilten Thatsachen der Annahme einer sekundären Chloratbildung in neutraler Lösung in jeder Hinsicht gerecht werden.

Freilich lehrt auch Versuch 4, dafs neben der rein chemischen Umwandlung von Hypochlorit in Chlorat noch ein zweiter Vorgang sich abspielt, der, wie Versuche in alkalischen Lösungen zeigen werden, fast nur unterhalb $50^{\circ} \mathrm{C}$. stattfindet und der hier als direkte Oxydation bezeichnet werden soll. Durch diese wurden $33 \%$ des der durchgegangenen Strommenge entsprechenden Sauerstoffes als Chloratsauerstoff erhalten. Da jedoch bei der Elektrolyse von Chloridlösungen das Hypochlorit keinesfalls in dem Umfange an der Elektrolyse teilnimmt wie bei diesem Versuche, so mufs man annehmen, dals dort die direkte Oxydation nur eine untergeordnete Rolle spielen wird.

Es scheinen somit nach eingehender Betrachtung der Resultate anderer, sowie an der Hand eigenen Versuchsmaterials die Verhältnisse bei der elektrolytischen Bildung von Hypochloriten und Chloraten in neutralen Lösungen geklärt zu sein.

Die Ergebnisse seien im folgenden nochmals kurz zusammengestellt.

1. Chlor wird an der Anode entladen und bildet mit dem von der Kathode kommenden Alkalihydrat Hypochlorit.

2. Das Hypochlorit nimmt bei einer bestimmten, bereits sehr niedrigen Konzentration an den Entladungsvorgängen teil.

3. Dabei entsteht unterchlorige Säure, die ihrerseits Hypochlorit und Alkalichlorid zu Chlorat oxydiert.

4. Nebenher wird in geringem Umfange Hypochlorit in der Kälte durch den an der Anode auftretenden Sauerstoff zu Chlorat oxydiert.

Im Anschlufs an diesen Befund wurde schliefslich noch zur 
Ergänzung der bereits vorhandenen Untersuchungen über den Einflufs der Temperatur und Stromdichte auf den Verlauf der Alkalichloridelektrolyse noch derjenige der Chloridkonzentration untersucht.

Die Theorie lälst hier voraussagen, dafs bei gleicher Stromdichte mit abnehmender Chloridkonzentration die Entladung von ClO-Ionen gefördert, mehr $\mathrm{HClO}$ an der Anode gebildet, also die Chloratbildung begünstigt wird. Die diese Vorgänge begleitende erhöhte Sauerstoffentwickelung wird aber bei niederer Temperatur nicht sehr bemerkbar werden, da dann einer verstärkten Teilnahme des Hypochlorits an der Elektrolyse eine Erhöhung der direkten Oxydation und damit ein entsprechender Sauerstoffverbrauch folgen wird. Bei erhöhter Temperatur jedoch, wo eine solche direkte Oxy-

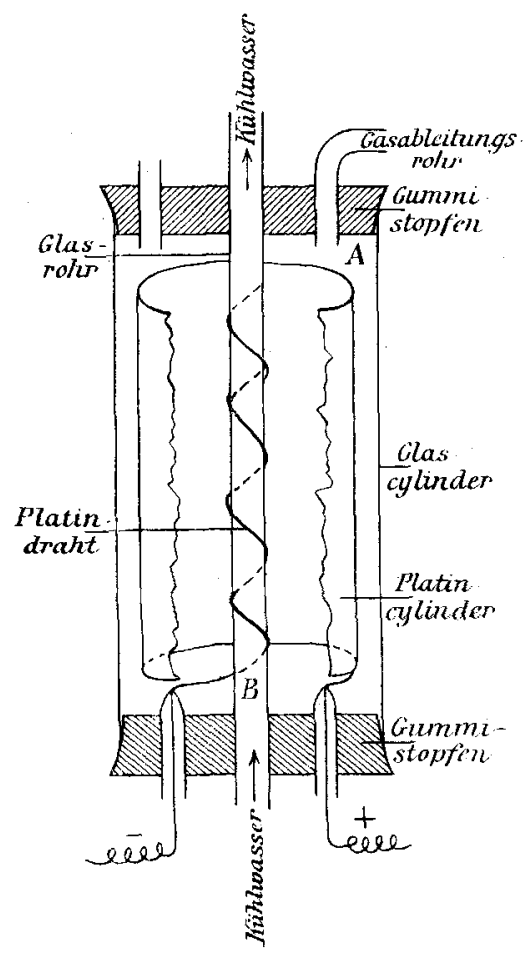

Fig. 5.

dation in den Hintergrund tritt, wird die einer vermehrten Entladung von ClO-Ionen entsprechende Erhöhung der Sauerstoffentwickelung bemerkbar werden. In jedem Falle aber muls sich ein 
Zurückgehen des Hypochlorits und eine Vermehrung des Chlorats ergeben. Freilich wird, zumal in der Hitze, eine verminderte Chloridkonzentration auch eine Verminderung der oxydierbaren Stoffe bedeuten und dadurch die Hypochloritmenge weniger abnehmen. Da endlich bei einer relativ hohen Chloridkonzentration infolge der verhältnismälsig starken Chlorentladung die Hypochloritkonzentration an der Anode stärker steigt, die Chloridkonzentration schneller sich vermindert als bei anfänglich niedrigerer Chloridkonzentration, so wird die unmittelbar die Anode bespülende Lösung in ihrer Zusammensetzung in beiden Fällen weniger verschieden sein, als die ursprüngliche Konzentration der Lösung vermuten läfst, wenn man allein die vorangehenden Erwägungen berücksichtigt. So ist ein starker Einflufs der Konzentrationsänderung überhaupt kaum zu erwarten. Wie weit ein solcher eintritt, zeigen die folgenden Versuche.

Bei denselben diente zur Aufnahme des Elektrolyten der in Fig. 5 gezeichnete Apparat, der aus der Zeichnung verständlich sein dürfte. Seine Einrichtung bezweckt vor allen Dingen eine gute Kühlung der Anode sowohl wie der Kathode. Der Glascylinder falste nach Verschlufs mit den beiden Stopfen ca. 120-130 ccm Lösung. Bei den Versuchen in der Kälte wurde der ganze Apparat in Eiswasser getaucht und durch letzteres auch das durch $B$ beständig fliefsende Leitungswasser vorgekühlt. Die Platinanode war als Cylindermantel dicht an den Glascylinder angelegt und hatte eine einseitig wirksame Oberfläche von $50 \mathrm{qcm}$. Die Kathode bestand aus einem Platindraht, der um das durch die Mitte gehende Kühlrohr dichtanliegend gewunden war. 


\section{Versuch 7.}

Die Stromatärke betrug 1 Amp.

Temperatur $50^{\circ} \mathrm{C}$.

Die Lösung $(100 \mathrm{ccm})$ enthielt $30 \mathrm{~g} \mathrm{NaCl}$.

$D_{K}=1.87 \mathrm{Amp} . / \mathrm{qcm} . D_{a}=0.02 \mathrm{Amp} . / \mathrm{qcm}$.

Spannung 3.35-3.4 Volt.

\begin{tabular}{c|c|c|c}
\hline $\begin{array}{c}\text { Versuchs- } \\
\text { dauex } \\
\text { Stunden }\end{array}$ & $\begin{array}{c}\text { Strom- } \\
\text { ausbeute } \\
\%\end{array}$ & $\begin{array}{c}\text { Reduktion } \\
\%\end{array}$ & $\begin{array}{c}\text { Sauerstoff- } \\
\text { entwickelung } \\
\%\end{array}$ \\
\hline \hline $11 / 2$ & 54.6 & 19.1 & 26.3 \\
2 & 53.9 & 19.7 & 26.4 \\
3 & 54.3 & 19.8 & 25.9 \\
5 & 55.2 & 18.9 & 25.9 \\
6 & 52.2 & 20.9 & 26.9 \\
7 & 52.6 & 20.6 & 26.8 \\
8 & 54.5 & 20.5 & 25.0
\end{tabular}

Im Voltameter niedergeschlagen $9.21 \mathrm{~g} \mathrm{Cu}=2.324 \mathrm{~g}$ Sanerstoff. Die Lauge enthielt wirksamen Sauerstoff als:

$$
\begin{aligned}
\text { Hypochlorit } & =0.0985 \mathrm{~g} . \\
\text { Chlorat } & =1.1677 \mathrm{~g} . \\
\hline \text { Sa. } & =1.2662 \mathrm{~g} \text { Gesamtsauerstoff } \\
& =54.8 \% \text { Stromausbeute. }
\end{aligned}
$$

Versuch 8.

Die Stromstärke betrug 1 Amp.

$D_{K}=1.87 \mathrm{Amp} . / q \mathrm{~cm} . D_{a}=0.02 \mathrm{Amp} . / \mathrm{qcm}$.

Temperatur $50^{\circ} \mathrm{C}$.

Die Lösung $(100 \mathrm{~cm})$ enthielt $7 \mathrm{~g} \mathrm{NaCl}$.

Spannung 4.0 Volt.

\begin{tabular}{c|c|c|c}
\hline \hline $\begin{array}{c}\text { Versuchs- } \\
\text { dauer }\end{array}$ & $\begin{array}{c}\text { Strom- } \\
\text { ausbeute }\end{array}$ & Reduktion & $\begin{array}{c}\text { Sauerstoff- } \\
\text { entwickelung }\end{array}$ \\
Stunden & $\% / 0$ & $\% / 0$ & $\%$ \\
\hline \hline 1 & 58.7 & 15.8 & 25.5 \\
2 & 47.5 & 21.2 & 31.3 \\
3 & 49.1 & 20.0 & 30.9 \\
5 & 49.1 & 20.3 & 30.6 \\
6 & 49.3 & 20.3 & 30.4 \\
7 & 48.1 & 22.7 & 29.2 \\
8 & 47.3 & 23.2 & 29.5
\end{tabular}

Im Voltameter niedergesehlagen $10.18 \mathrm{~g} . \mathrm{Cn}=2.57 \mathrm{~g}$. Sauerstoff. Die Lauge enthielt wirksamen Sauerstoff als:

$$
\begin{aligned}
\text { Hypochlorit } & =0.112 \mathrm{~g} . \\
\text { Chlorat } & =1.0642 \mathrm{~g} . \\
\text { Sa. } & =1.1762 \mathrm{~g} \text { Gesamtsauerstoff. } \\
. . & =45.8 \% \text { Stromausbeute. }
\end{aligned}
$$

Z. anorg. Chem. XXII. 


\section{Versuch 9.}

Die Stromstärke betrug 1 Amp.

$D_{K}=1.87 \mathrm{Amp} . / \mathrm{qcm} . D_{a}=0.02 \mathrm{Amp} / \mathrm{qcm}$.

Temperatur $8-12^{\circ} \mathrm{C}$.

Die Lösung $(100 \mathrm{ccm})$ enthielt $30 \mathrm{~g} \mathrm{NaCl}$.

Spannung 3.9-4.1 Volt.

\begin{tabular}{c|c|c|c}
\hline \hline $\begin{array}{c}\text { Versuchs- } \\
\text { dauer }\end{array}$ & $\begin{array}{c}\text { Strom- } \\
\text { ausbeute } \\
\text { Stunden }\end{array}$ & Reduktion & $\begin{array}{c}\text { Sauerstoff- } \\
\text { entwickelung }\end{array}$ \\
\hline \hline 1 & 70.3 & $0 / 0$ & $\%$ \\
3 & 55.0 & 14.9 & 14.8 \\
4 & 52.3 & 22.2 & 22.8 \\
5 & 52.0 & 23.2 & 24.5 \\
6 & 51.7 & 23.5 & 24.5 \\
7 & 50.8 & 23.3 & 25.0 \\
8 & 50.9 & 23.1 & 26.1 \\
\hline
\end{tabular}

Im Voltameter niedergeschlagen $9.1 \mathrm{~g} \mathrm{Cu}=2.295 \mathrm{~g}$ Sauerstoff. Die Lauge enthielt wirksamen Sauerstoff als:

$$
\begin{aligned}
\text { Hypochlorit } & =0.3206 \mathrm{~g} . \\
\text { Chlorat } & =0.7818 \mathrm{~g} . \\
\hline \text { Sa. } & =1.1024 \mathrm{~g} \text { Gesamtsauerstoff. } \\
& =48 \% \text { Stromausbeute. }
\end{aligned}
$$

\section{Versuch 10.}

Die Stromstärke betrug 1 Amp.

$D_{K}=1.87 \mathrm{Amp} . / \mathrm{qcm}$. $D_{a}=0.02 \mathrm{Amp} . / \mathrm{qcm}$.

Temperatur $8-12^{\circ} \mathrm{C}$.

Die Lösung $(100 \mathrm{ccm})$ enthielt $7 \mathrm{~g} \mathrm{NaCl}$.

Spannung $4.8-5$ Volt.

\begin{tabular}{c|c|c|c}
\hline $\begin{array}{c}\text { Versuchs- } \\
\text { dauer }\end{array}$ & $\begin{array}{c}\text { Strom- } \\
\text { ausbeute } \\
\text { Minuten }\end{array}$ & Reduktion & $\begin{array}{c}\text { Sauerstoff- } \\
\text { entwickelung } \\
\%\end{array}$ \\
\hline 1 & 65.0 & 17.0 & 18.0 \\
2 & 55.6 & 22.9 & 21.5 \\
3 & 48.1 & 25.7 & 26.2 \\
5 & 48.6 & 25.5 & 25.9 \\
6 & 47.8 & 25.7 & 26.5 \\
7 & 49.9 & 24.9 & 25.2 \\
8 & 49.5 & 24.9 & 25.6
\end{tabular}

Im Voltameter niedergeschlagen $9.59 \mathrm{~g} \mathrm{Cu}=\mathbf{2 . 4 2} \mathrm{g}$ Sauerstoff. Die Lauge enthielt wirksamen Sauerstoff als:

$$
\begin{aligned}
\text { Hypochlorit } & =0.265 \mathrm{~g} . \\
\text { Chlorat } & =0.974 \mathrm{~g} . \\
\hline \text { Sa. } & =1.239 \mathrm{~g} \text { Gesamtsauerstoff. } \\
& =51.2 \% \text { Stromausbeute. }
\end{aligned}
$$




\section{Versuch 11.}

Die Stromstärke betrug 4 Amp.

$D_{K}=7.48$ Amp. $/ \mathrm{qcm} . D_{a}=0.08 \mathrm{Amp} . / \mathrm{qcm}$.

Temperatur $50^{\circ} \mathrm{C}$.

Die Lösung (100 ecm) enthielt $28 \mathrm{~g} \mathrm{NaCl}$.

Spannung 5.8-6.0 Volt.

\begin{tabular}{c|c|c|c|c}
\hline \hline $\begin{array}{c}\text { Versuchs- } \\
\text { dauer }\end{array}$ & $\begin{array}{c}\text { Strom- } \\
\text { ausbeute } \\
\text { Minuten }\end{array}$ & Reduktion & $\begin{array}{c}\text { Sauerstoff- } \\
\text { entwickelung } \\
\%\end{array}$ & $\begin{array}{c}\text { Aktiver } \\
\text { Sauerstoff als } \\
\text { Hypochlorit } \\
\mathrm{g}\end{array}$ \\
\hline \hline 10 & $\%$ & $\%$ & $=$ \\
20 & 74.8 & 10.0 & 15.2 & 0.147 \\
30 & 53.8 & 13.4 & 22.8 & 0.235 \\
45 & 57.9 & 15.5 & 26.6 & 0.209 \\
60 & 57.5 & 16.6 & 26.2 & 0.202 \\
90 & 58.0 & 16.6 & 25.9 & 0.197 \\
120 & 57.9 & 16.4 & 25.6 & 0.196 \\
\end{tabular}

Im Voltameter niedergeschlagen $9.72 \mathrm{~g} \mathrm{Cu}=2.453 \mathrm{~g}$ Sauerstoff. Die Lauge enthielt wirksamen Sauerstoff als:

$$
\begin{aligned}
\text { Hypochlorit } & =0.180 \mathrm{~g} . \\
\text { Chlorat } & =1.2459 \mathrm{~g} . \\
\hline \text { Sa. } & =1.4259 \mathrm{~g} \text { Gesamtsauerstoff. } \\
& =58.1 \% \text { Stromausbeute. }
\end{aligned}
$$

\section{Versuch 12 .}

Die Stromstärke betrug 4 Amp.

$I_{K}=7.48 \mathrm{Amp} . / \mathrm{qcm} . \quad D_{a}=0.08 \mathrm{Amp}$. $/ q \mathrm{~cm}$.

Temperatur $50^{\circ} \mathrm{C}$.

Die Lösung $(100 \mathrm{ccm})$ enthielt $7 \mathrm{~g} \mathrm{NaCl}$.

Spannung 7.6 Volt.

\begin{tabular}{c|c|c|c|c}
\hline $\begin{array}{c}\text { Versuchs- } \\
\text { dauer }\end{array}$ & $\begin{array}{c}\text { Strom- } \\
\text { ausbeute } \\
\text { Minuten }\end{array}$ & Reduktion & $\begin{array}{c}\text { Sauerstoff- } \\
\text { entwickelung } \\
\%\end{array}$ & $\begin{array}{c}\text { Aktiver } \\
\text { Sauerstoff als } \\
\text { Hypochlorit } \\
\text { gy }\end{array}$ \\
\hline \hline 10 & 64.3 & 11.9 & 23.8 & 0.120 \\
20 & 59.0 & 16.5 & 24.5 & 0.175 \\
30 & 56.8 & 18.0 & 26.2 & 0.199 \\
45 & 53.0 & 19.4 & 27.6 & 0.204 \\
60 & 53.0 & 18.6 & 28.4 & 0.200 \\
90 & 50.3 & 19.5 & 30.2 & 0.193 \\
120 & 50.3 & 18.5 & 31.2 & 0.183
\end{tabular}

Im Voltameter niedergeschlagen $10.23 \mathrm{~g} \mathrm{Cu}=2.582 \mathrm{~g}$ Sauerstoff. Die Lauge enthielt wirksamen Sauerstoff als:

$$
\begin{aligned}
\text { Hypochlorit } & =0.1791 \mathrm{~g} . \\
\text { Chlorat } & =1.1340 \mathrm{~g} . \\
\hline \text { Sa. } & =1.3131 \mathrm{~g} \text { Gesamtsauerstoff. } \\
& =50.9 \% \text { Stromausbeute. }
\end{aligned}
$$




\section{Versuch 13.}

Die Stromstärke betrug 4 Amp.

$D_{K}=7.48 \mathrm{Amp} . / \mathrm{qm} . D_{a}=0.08 \mathrm{Amp} / \mathrm{qem}$.

Temperatur $8-16^{\circ} \mathrm{C}$.

Die Lösung $(100 \mathrm{ccm})$ enthielt $28 \mathrm{~g} \mathrm{NaCl}$. Spannung 7.3 Volt.

\begin{tabular}{|c|c|c|c|c|}
\hline $\begin{array}{c}\text { Versuchs- } \\
\text { dauer } \\
\text { Minuten }\end{array}$ & $\begin{array}{c}\text { Strom- } \\
\text { ausbeute } \\
\%\end{array}$ & $\begin{array}{c}\text { Reduktion } \\
\%\end{array}$ & $\begin{array}{c}\text { Sauerstoff- } \\
\text { entwickelung } \\
\%\end{array}$ & $\begin{array}{c}\text { Aktiver } \\
\text { Sauerstoff als } \\
\text { Hypochlorit } \\
\mathrm{g}\end{array}$ \\
\hline 10 & - & 7.6 & - & 0.164 \\
\hline 20 & 73.2 & 11.5 & 15.3 & 0.301 \\
\hline 30 & 72.7 & 12.0 & 15.3 & 0.381 \\
\hline 45 & 65.1 & 14.3 & 20.6 & 0.471 \\
\hline 60 & 55.6 & 17.0 & 27.4 & 0.504 \\
\hline 90 & 54.2 & 17.3 & 28.5 & 0.499 \\
\hline 120 & 48.9 & 19.0 & 32.1 & 0.490 \\
\hline
\end{tabular}

Im Voltameter niedergeschlagen $9.85 \mathrm{~g} \mathrm{Cu}=2.486 \mathrm{~g}$ Sauerstoff. Die Lauge enthielt wirksamen Sauerstoff als:

$$
\begin{aligned}
\text { Hypochlorit } & =0.4837 \mathrm{~g} . \\
\text { Chlorat } & =0.9943 \mathrm{~g} . \\
-\mathrm{Sa} . & =1.4780 \mathrm{~g} \text { Gesamtsauerstoff. } \\
& =59.5 \% \text { Stromausbeute. }
\end{aligned}
$$

Versuch 14.

Die Stromstärke betrug 4 Amp.

$D_{K}=7.48$ Amp. $/ q \mathrm{~cm} . D_{a}=0.08 \mathrm{Amp} . / \mathrm{qcm}$.

Temperatur $8-16^{\circ} \mathrm{C}$.

Die Lösung $(100 \mathrm{cem})$ enthielt $7 \mathrm{~g} \mathrm{NaCl}$.

Spannung 10.2 Volt.

\begin{tabular}{c|c|c|c|c}
\hline $\begin{array}{c}\text { Versuchs- } \\
\text { dauer } \\
\text { Minuten }\end{array}$ & $\begin{array}{c}\text { Strom- } \\
\text { ausbeute } \\
\%\end{array}$ & Reduktion & $\begin{array}{c}\text { Sauerstoff- } \\
\text { entwickelung } \\
\%\end{array}$ & $\begin{array}{c}\text { Aktiver } \\
\text { Sauerstoff als } \\
\text { Hypochlorit } \\
\text { Hy }\end{array}$ \\
\hline 10 & 76.9 & 10.9 & 13.3 & 0.154 \\
20 & 62.9 & 15.0 & 22.1 & 0.238 \\
30 & 55.7 & 19.5 & 24.8 & 0.288 \\
45 & 55.9 & 20.5 & 26.6 & 0.329 \\
60 & 52.9 & 20.6 & 27.9 & 0.335 \\
90 & 51.5 & 19.5 & 28.1 & 0.334
\end{tabular}

Im Voltameter niedergeschlagen $10.05 \mathrm{~g} \mathrm{Cu}=2.536 \mathrm{~g}$ Sauerstoff. Die Lauge enthielt wirksamen Sauerstoff als:

$$
\begin{aligned}
\text { Hypochlorit } & =0.3330 \mathrm{~g} . \\
\text { Chlorat } & =1.0021 \mathrm{~g} . \\
\text { Sa. } & =1.3351 \mathrm{~g} \text { Gesamtsauerstoff. } \\
& =52.7 \% \text { Stromausbeute. }
\end{aligned}
$$




\section{B. Chloratbildung in schwach saurer Lösung.}

Es ist schon betont worden, dafs die für die Elektrolyse neutraler Alkalichloridlösungen beobachteten Erscheinungen eine Erklärung auch finden könnten durch die HABER'sche Annahme einer hydrolytischen Spaltung des Hypochlorits. Das ist aber nicht mehr der Fall bei den für angesäuerte Lösungen beobachteten Verhältnissen.

Wie schon Förster hervorgehoben hat, läfst sich die Thatsache, dafs ein freie Kohlensäure und Natriumbikarbonat enthaltender Elektrolyt für die Chloratbildung günstiger als ein neutraler ist, mit der Annahme einer besonders boheu Hydroxylkonzentration nicht recht deuten; wohl aber mit Hilfe der Vorstellung, dafs dadurch nicht nur unmittelbar an der Anode, sondern auch in gröfserer Entfernung von derselben unterchlorige Säure entstehen und Chlorat bilden kann.

Da über das auf diesen Vorgängen beruhende Verfahren der Elektrizitätsgesellschaft, vorm. ScHDOKERT \& Co. ${ }^{1}$ bisher keinerlei nähere Angaben vorliegen, wurde es in der oben erwähnten Weise eingehender untersucht, zum $Z_{\text {wecke, }}$ die Richtigkeit der Theorie zu prüfen.

Während der Elektrolyse wurde beständig ein langsamer Strom von Kohlensäure durch die Flüssigkeit geleitet, der 2 Minuten vor einer jeden Gasentnahme abgestellt wurde. Die Kohlensäure wurde in der Kalipipette absorbiert. Bei der Berechnung der Resultate ist zu beachten, dals für ein entladenes $\mathrm{CO}_{3} 1$ Volumen $\overline{\mathrm{CO}}_{2}$ und ein halbes Volumen 0 entsteht. Die gasanalytischen Zahlen können nur ein ungefähres Bild von dem Verlauf der Elektrolyse geben, da man nicht ganz sicher ist, inwiefern die analysierten Gase auch genau dieselbe Zusammensetzung haben wie die im Zeitpunkte des Versuches bei der elektrolytischen Zersetzung gebildeten. Es stimmen deshalb auch die gasanalytisch ermittelten Stromausbeuten mit den durch das Kupfervoltameter bestimmten nicht gut überein. Immerhin aber sind die gasanalytisch gefundenen Werte, da sio stets in derselben Weise ermittelt wurden, unter sich vergleichbar.

1 D.R.P. 83536. 89844. 
Versuch 15.1

Temperatur $8-12^{\circ} \mathrm{C}$.

Die Lösung (500 cem) enthielt $28 \mathrm{~g} \mathrm{NaCl}$ in $100 \mathrm{ccm}+4.2 \mathrm{~g} \mathrm{NaHCO}_{8}=1 / 10^{-\mathrm{n}}$. $D_{K}=0.18 \mathrm{Amp}$. $\mathrm{qcm} . D_{a}=0.075 \mathrm{Amp} / \mathrm{qcm}$.

Spannung 4.5-4.6 Volt.

\begin{tabular}{|c|c|c|c|c|c|}
\hline \multirow{2}{*}{$\begin{array}{l}\text { Versuchs- } \\
\text { dauer } \\
\text { Stunden }\end{array}$} & \multirow{2}{*}{$\begin{array}{c}\text { Strom- } \\
\text { ausbeute } \\
\%\end{array}$} & \multirow{2}{*}{$\begin{array}{c}\text { Reduktion } \\
\% \\
\end{array}$} & \multirow{2}{*}{$\begin{array}{c}\text { Sauerstoff- } \\
\text { entwickelung } \\
\% \\
\end{array}$} & \multicolumn{2}{|c|}{$\begin{array}{c}\text { Aktiv. Sauerstoff in } 500 \mathrm{ccm} \\
\text { als }\end{array}$} \\
\hline & & & & $\begin{array}{c}\text { Hypochlorit } \\
\text { g }\end{array}$ & $\begin{array}{l}\text { Chlorat } \\
\text { g }\end{array}$ \\
\hline $1 / 4$ & - & 13.4 & - & 0.27 & 0.07 \\
\hline & 71.6 & 20.8 & 7.6 & - & - \\
\hline $3 / 4$ & 70.3 & 25.2 & 4.5 & 0.76 & 0.08 \\
\hline 1 & 67.8 & 26.5 & 5.7 & 0.93 & 0.20 \\
\hline $11 / 2$ & 57.0 & 32.0 & 11.0 & 1.22 & 0.38 \\
\hline 2 & 51.5 & 32.9 & 15.7 & 1.47 & 0.4 \\
\hline $21 / 9$ & - & - & - & 1.47 & 0.9 \\
\hline $\mathbf{3}$ & 43.5 & 40.4 & 16.1 & 1.93 & 1.38 \\
\hline 4 & 58.7 & 31.0 & 10.3 & 1.28 & 2.14 \\
\hline 5 & 51.9 & 34.7 . & 14.2 & 1.42 & 3.21 \\
\hline 7 & 49.7 & 34.9 & 15.3 & 1.30 & 4.71 \\
\hline 8 & 50.5 & 34.1 & 15.4 & - & - \\
\hline
\end{tabular}

Im Voltameter niedergeschlagen $46.0 \mathrm{~g} \mathrm{Cu}=11.6 \mathrm{~g}$ Sauerstoff. Die Lauge enthielt wirksamen Sauerstoff $6.37 \mathrm{~g}=54.9 \%$ Stromausbeute.

Versuch 16.

Temperatur $8-12^{\circ} \mathrm{C}$.

Die Lösung $(500 \mathrm{ccm})$ enthielt $28 \mathrm{~g} \mathrm{NaCl}$ in $100 \mathrm{ccm}+12.5 \mathrm{~g} \mathrm{NaHCO}=3 / 10-\mathrm{n}$. $D_{K K}=0.18 \mathrm{Amp} . / \mathrm{qcm}, D_{a}=0.075 \mathrm{Amp} . / \mathrm{qcm}$.

Spannung 4.5 Volt.

\begin{tabular}{c|c|c|c|c|c}
\hline \hline $\begin{array}{c}\text { Versuchs- } \\
\text { dauer }\end{array}$ & $\begin{array}{c}\text { Strom- } \\
\text { ausbeute } \\
\text { Stunden }\end{array}$ & $\begin{array}{c}\text { Reduktion } \\
\%\end{array}$ & $\%$ & $\begin{array}{c}\text { Sauerstoff- } \\
\text { entwickelung } \\
\%\end{array}$ & $\begin{array}{c}\text { Aktiv. Saucrstoff in 500 ccm } \\
\text { als }\end{array}$ \\
\hline \hline $1 / 4$ & 81.7 & 11.3 & 6.9 & 0.25 & 0.05 \\
$1 / 2$ & 75.9 & 16.3 & 7.8 & 0.50 & 0.07 \\
$3 / 4$ & 69.7 & 21.1 & 9.2 & 0.62 & 0.29 \\
1 & - & 23.5 & - & 0.77 & 0.36 \\
$11 / 2$ & 58.4 & 27.1 & 14.5 & 0.97 & 0.61 \\
2 & 53.9 & 29.8 & 16.3 & 1.16 & 0.72 \\
3 & 48.2 & 35.3 & 16.5 & 1.33 & 1.52 \\
4 & 45.0 & 39.1 & 15.9 & 1.25 & 2.21 \\
\end{tabular}

Im Voltameter niedergeschlagen $25.0 \mathrm{~g} \mathrm{Cu}=6.3 \mathrm{~g}$ Sauerstoff. Die Lauge enthielt wirksamen Sauerstoff $3.56 \mathrm{~g}=56.5 \%$ Stromausbeute.

1 Apparat wie bei Versuch 1. 
Versuch 17.

Temperatur $50^{\circ} \mathrm{C}$.

Die Lösung $(500 \mathrm{ccm})$ enthielt $28 \mathrm{~g} \mathrm{NaCl}$ in $100 \mathrm{cem}+12.5 \mathrm{~g} \mathrm{NaHCO}_{3}=8 / 10^{-\mathrm{n}}$. $D_{K}=0.18 \mathrm{Amp} / \mathrm{qcm} . D_{a}=0.075 \mathrm{Amp} / \mathrm{qem}$.

Spannung 3.8 Volt.

\begin{tabular}{|c|c|c|c|c|c|}
\hline $\begin{array}{l}\text { Versuchs- } \\
\text { dauer } \\
\text { Stunden }\end{array}$ & $\begin{array}{c}\text { Strom- } \\
\text { ausbeute } \\
\%\end{array}$ & $\begin{array}{c}\text { Reduktion } \\
\%\end{array}$ & $\begin{array}{c}\text { Sauerstoff- } \\
\text { entwickelung } \\
\%\end{array}$ & $\begin{array}{l}\text { Aktiv. Sauers } \\
\text { Hypochlorit } \\
\mathrm{g}\end{array}$ & $\begin{array}{l}\text { in } 500 \mathrm{cem} \\
\text { Chlorat } \\
g\end{array}$ \\
\hline $1 / 12$ & - & - & - & 0.00 & 0.08 \\
\hline & $=$ & - & - & 0.06 & 0.18 \\
\hline $1 / 2$ & 57.4 & 20.7 & 21.9 & 0.14 & - \\
\hline $3 / 4$ & 54.2 & 21.5 & 24.3 & 0.19 & 0.46 \\
\hline $1^{14}$ & 54.4 & 21.9 & 23.7 & 0.23 & 0.68 \\
\hline $11 / 2$ & 53.4 & 22.3 & 24.3 & 0.23 & 1.06 \\
\hline 2 & 52.0 & 23.0 & 25.0 & 0.23 & 2.05 \\
\hline $31 / 2$ & 49.2 & 23.8 & 27.0 & 0.23 & 3.02 \\
\hline $41 / 2$ & 51.0 & 23.2 & 25.8 & 0.24 & 3.41 \\
\hline 20 & 50.9 & 21.2 & 27.9 & - & - \\
\hline 21 & 51.4 & 20.8 & 27.8 & 0.22 & - \\
\hline 22 & 51.8 & 19.7 & 28.5 & - & 15.20 \\
\hline
\end{tabular}

Im Voltameter niedergeschlagen $115.5 \mathrm{~g} \mathrm{Cu}=29.1 \mathrm{~g}$ Sauerstoff. Die Lauge enthielt wirksamen Sauerstoff $15.11 \mathrm{~g}=51.9 \%$ Stromausbeute.

28.7\% ige NaCl-Lösung $1 / 10^{-n o r m} . \mathrm{NaHCO}_{3} . \quad 8-12^{\circ} \mathrm{C}$.

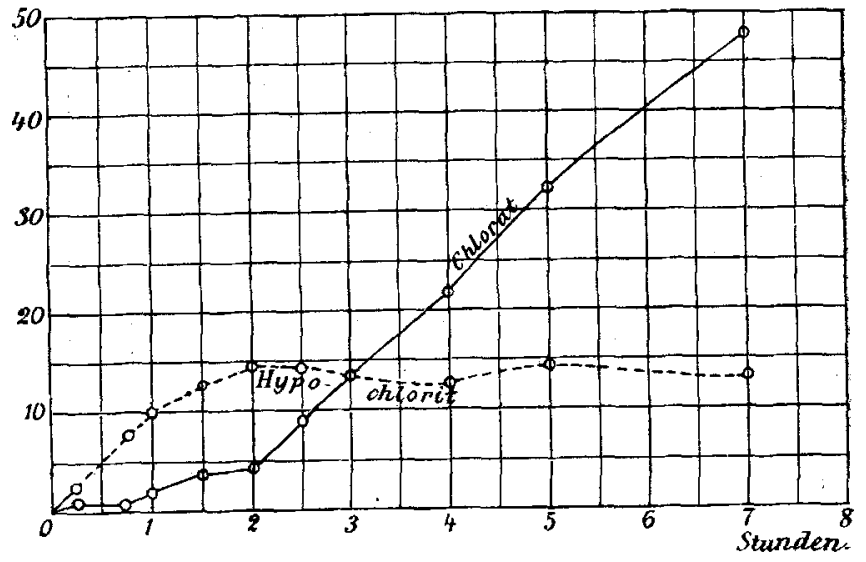

Fig. 6. 
28.7\% \% 1 ge NaCl-Lösung $8 / 10^{-n o r m}$. $\mathrm{NaHCO}_{3}, 8-12^{\circ} \mathrm{C}$.

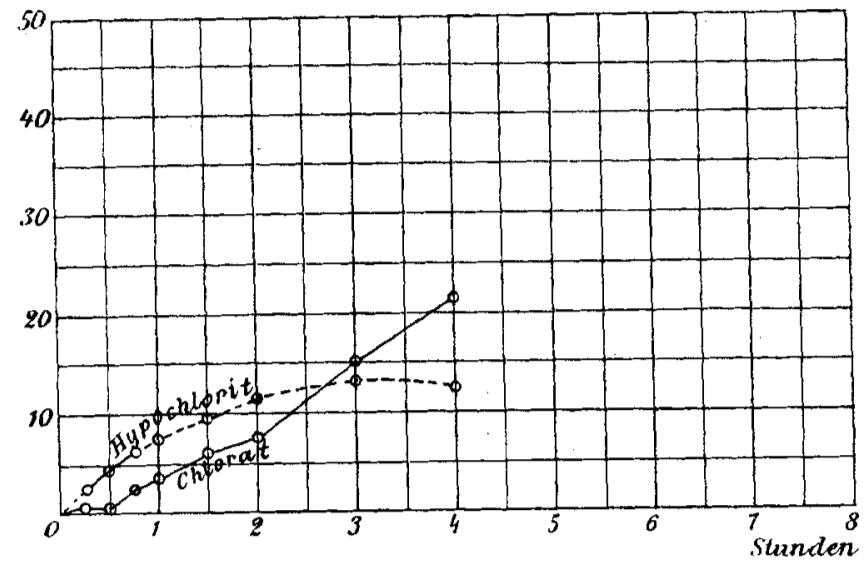

Fig. 7.

$31.4 \%$ ige NaCl-Lösung ${ }^{8 / 1} / 0^{- \text {norm. }} \mathrm{NaHCO}_{3} .50^{\circ} \mathrm{C}$.

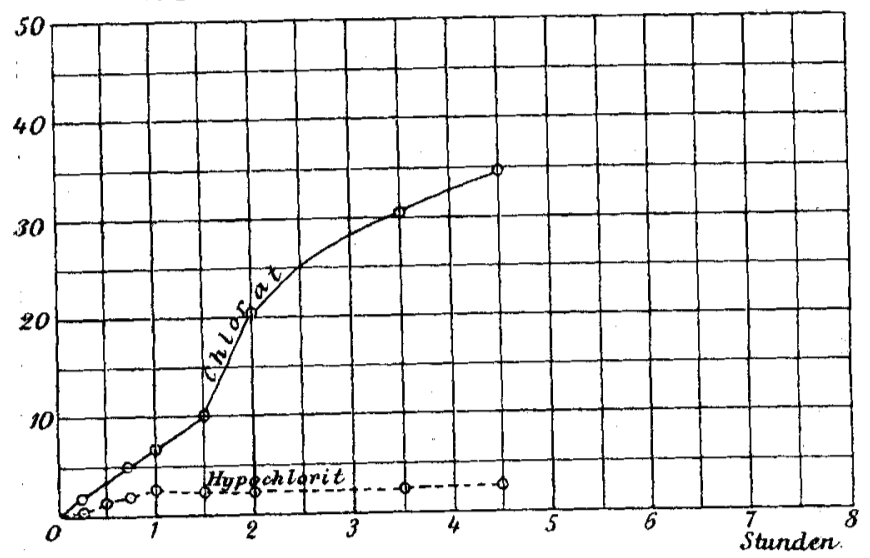

Fig. 8. 
Vergleicht man hier die in ein Koordinatensystem eingetragenen Resultate mit den in neutralen Lösungen gefundenen, so beobachtet man in Übereinstimmung mit der Theorie ein bei weitem früheres Überschneiden der Hypochlorit- und Chloratkurven, was gleichbedeutend ist mit einer beschleunigteren Umwandlung von Hypochlorit in Chlorat. Bei $50^{\circ} \mathrm{C}$. liegt der Schnittpunkt so früh, dals er der Beobachtung entgeht. Die Mengen Hypochlorit, die sich während der Elektrolyse bei $8-12^{\circ} \mathrm{C}$. gebildet haben, sind dementsprechend, wie zu erwarten stand, auch nur halb so grofs wie in neutralen Lösungen. Ein vermehrter Zusatz von Bikarbonat ändert bei $8-12^{\circ}$ wenig an dem Gesamtbilde; er vermindert ein wenig die Reduktion und steigert die Sauerstoffentwickelung an der Anode, indem an Stelle der verschiedenden Hypochlorit-Ionen diejenigen der Kohlensäure reichlicher treten.

Dafs übrigens die Wirkung der Kohlensäure thatsächlich die angegebene ist, davon kann man sich sehr leicht überzeugen, wenn man in eine neutrale Hypochloritlösung Kohlensäure einleitet. In kürzester Zeit ist fast sämtliches Hypochlorit in Chlorat übergeführt.

Es besteht die Möglichkeit, dem Elektrolyten auch dadurch eine ganz schwache Säuerung zu erteilen, dafs man ihm eine mälsig dissoziierte Säure nebst ihrem Alkalisalz zusetzt. Hier würde es sich zumal um organische Säuren handeln. Solche werden jedoch, einschliefslich der Essigsäure, von dem Hypochlorit zu Kohlensäure oxydiert und die Lösung wird dadurch mit der Zeit neutral werden.

Eine dauernde schwache Säuerung von Chloridlösungen lälst sich nun aber in der Weise erreichen, dafs man ihnen beständig kleine Mengen der Basis entzieht. Dies geschieht nach Biscноғғ und FönsteR ${ }^{1}$ bei der Elektrolyse von Chlorcalciumsalzen, wo sich an der Kathode beständig eine gewisse Menge Kalkhydrat ausscheidet.

Um die hier auftretenden Erscheinungen mit den bisher studierten zu vergleichen, wurden unter den bei den bisherigen Versuchen eingehaltenen Bedingungen auch Versuche mit reinem Chlorcalcium angestellt.

Die Stromstärke betrug $4.5 \mathrm{Amp}$.

${ }^{1}$ Zeitschr. Elehtrochem. 4, Heft 20. 


\section{Versuch 18.1}

Temperatur $8-12^{\circ} \mathrm{C}$.

Die Lösung (500 ccm) enthielt $30 \mathrm{~g} \mathrm{CaCl}_{2}$ (wasserfrei) auf $100 \mathrm{ccm}$. $D_{K}=0.18$ Amp. $/ \mathrm{qcm}$. $D_{a}=0.075$ Amp. $/ \mathrm{qcm}$.

Spannung zu Beginn 4.8 Volt, dann allmählich ansteigend zu 5.7 Volt.

\begin{tabular}{|c|c|c|c|c|c|}
\hline $\begin{array}{l}\text { Versuchs- } \\
\text { dauer } \\
\text { Stunden }\end{array}$ & $\begin{array}{c}\text { Strom } \\
\text { ausbeute } \\
\%\end{array}$ & $\begin{array}{c}\text { Reduktion } \\
\%\end{array}$ & $\begin{array}{c}\text { Sauerstoff- } \\
\text { entwickelung } \\
\%\end{array}$ & $\begin{array}{l}\text { Aktiv. Sauerst } \\
\text { Hypochlorit } \\
\text { g }\end{array}$ & $\begin{array}{l}\text { fin } 500 \mathrm{ccm} \\
\text { Chlorat } \\
\mathrm{g}\end{array}$ \\
\hline $1 / 4$ & - & - & - & 0.52 & 0.00 \\
\hline $1 / 2$ & - & - & - & 0.80 & 0.00 \\
\hline $3_{/ 4}^{\prime}$ & - & $\ldots$ & - & 1.06 & 0.00 \\
\hline 1 & 91.5 & 3.2 & 6.3 & - & - \\
\hline $11 / 4$ & - & - & - & 1.52 & 0.25 \\
\hline $11 / 2$ & - & - & - & 1.72 & 0.46 \\
\hline $1^{8 / 4}$ & - & - & - & 1.93 & 0.76 \\
\hline 2 & 84.9 & 5.5 & 9.6 & - & - \\
\hline $2^{1 / 4}$ & - & - & - & 2.20 & 0.93 \\
\hline $2^{3 / 4}$ & - & - & - & $2 . \pm 2$ & - \\
\hline 3 & 85.9 & 3.8 & 10.3 & 2.43 & 1.79 \\
\hline 4 & 85.2 & 3.5 & 11.3 & 2.57 & 3.25 \\
\hline 5 & $85 . \tilde{5}$ & 4.3 & 10.2 & 2.13 & 4.65 \\
\hline
\end{tabular}

Zu Beginn der Elektrolyse entwich Chlor.

Im Voltameter niedergeschlagen $27.0 \mathrm{~g} \mathrm{Cu}=6.82 \mathrm{~g}$ Sauerstoff. Die Lauge enthielt wirksamen Sauerstoff $6.15 \mathrm{~g}=84.2 \%$ Stromausbente.

Versuch 19.

Temperatur $50^{\circ} \mathrm{C}$.

Die Lösung (500 ccm) enthielt $30 \mathrm{~g} \mathrm{CaCl}$ (wasserfrei) auf $100 \mathrm{ccm}$. $D_{K}=0.18 \mathrm{Amp} . / \mathrm{qm} . D_{a}=0.075 \mathrm{Amp} . / \mathrm{qcm}$.

Spannung zu Beginn 4.5 Volt, dann während der Elektrolyse schwankend zwischen 5 und 6 Volt.

\begin{tabular}{|c|c|c|c|c|c|}
\hline \multirow{2}{*}{$\begin{array}{l}\text { Versuchs- } \\
\text { dauer } \\
\text { Stunden }\end{array}$} & \multirow{2}{*}{$\begin{array}{c}\text { Strom- } \\
\text { ausbeute } \\
\%\end{array}$} & \multirow{2}{*}{$\begin{array}{c}\text { Reduktion } \\
\%\end{array}$} & \multirow{2}{*}{$\begin{array}{c}\text { Sauerstoff- } \\
\text { entwickelung } \\
\%\end{array}$} & \multicolumn{2}{|c|}{$\begin{array}{c}\text { Aktiv. Sauerstoff in } 500 \mathrm{cem} \\
\text { als }\end{array}$} \\
\hline & & & & $\begin{array}{c}\text { Hypochlorit } \\
\mathrm{g}\end{array}$ & $\begin{array}{c}\text { Chlorat } \\
\mathrm{g}\end{array}$ \\
\hline $1 / 4$ & 87.6 & 7.9 & 4.5 & 0.38 & 0.02 \\
\hline $1 / 2$ & - & - & - & 0.59 & 0.09 \\
\hline $3 / 4$ & - & - & - & 083 & 0.05 \\
\hline 1 & 80.2 & 10.6 & 9.2 & - & - \\
\hline $1^{1 / 4}$ & - & - & - & 1.15 & 0.33 \\
\hline $14 / 2$ & - & - & $\ldots$ & 1.42 & 0.33 \\
\hline 2 & 71.7 & 11.5 & 16.8 & 1.36 & 0.89 \\
\hline $2^{1} / 2$ & - & - & - & 1.37 & - \\
\hline 3 & 74.3 & 8.7 & 17.0 & 1.34 & 1.87 \\
\hline 4 & 82.6 & 6.5 & 10.9 & 0.89 & - \\
\hline 5 & 87.5 & 4.4 & 8.2 & 0.79 & 4.21 \\
\hline $5^{1 / 2}$ & - & - & - & 0.72 & - \\
\hline $199^{3 / 4}$ & 94.1 & 0.5 & 5.4 & 0.48 & - \\
\hline
\end{tabular}

Im Voltameter niedergeschlagen $109.5 \mathrm{~g} \mathrm{Cu}=27.6 \mathrm{~g}$ Sauerstoff. Die Lauge enthielt $24.09 \mathrm{~g}$ wirksamen Sauerstoff $=87.3 \%$ Stromausbeute.

Bereits nach 5 Stunden entweicht in geringer Menge Chlor. Deshalb erscheint die bei der Gasanalyse gefundene Zahl für die Stromausbeute ein wenig $\mathrm{zu}$ hoch, die bei der Titration gefundene zu niedrig.

1 Apparat wie bei Versuch 1. 

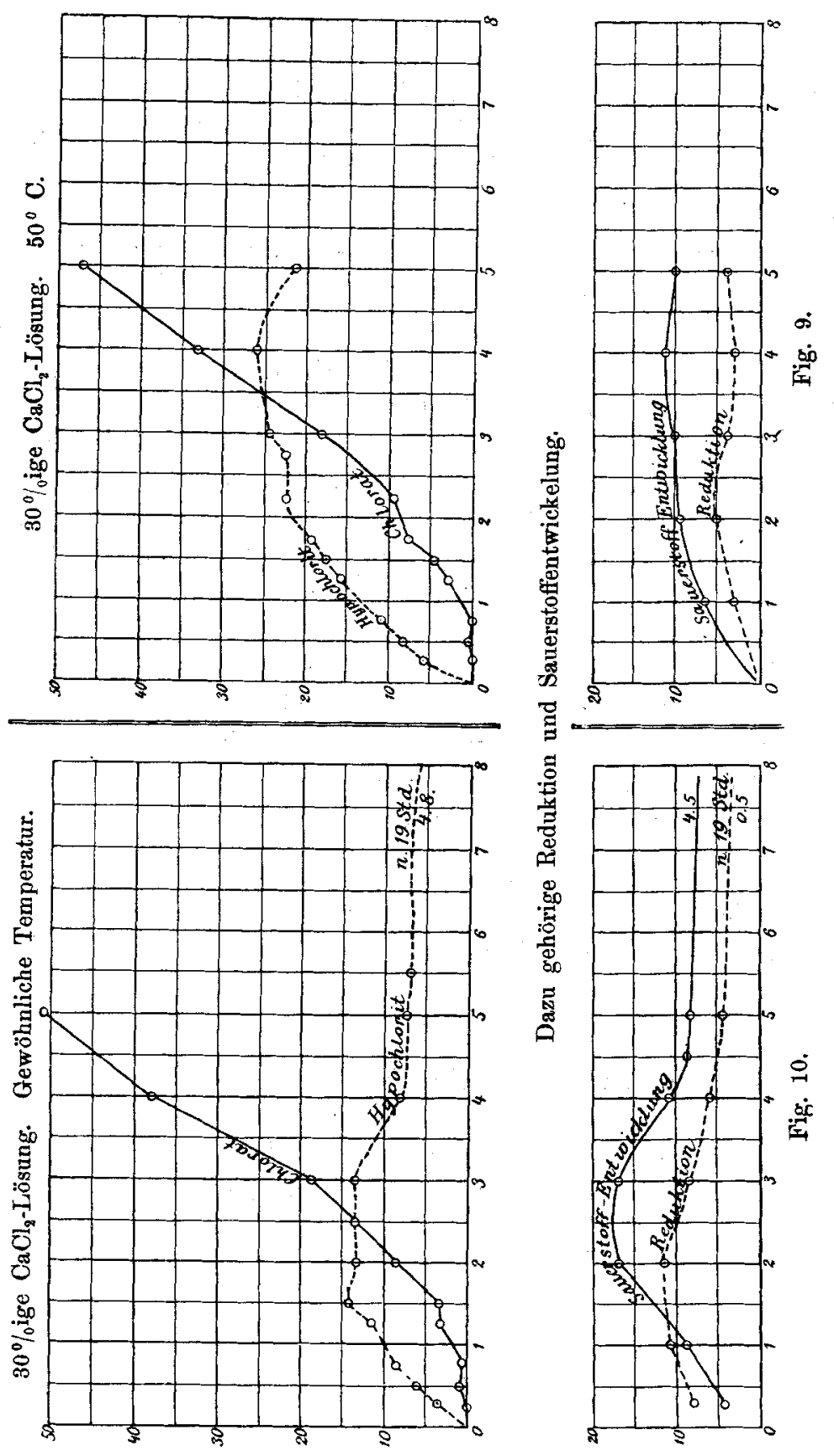
Diese Versuche, welche die von BrsomofF und Förster gefundenen Thatsachen bestätigen, zeigen, dafs trotzdem das Hypochlorit kaum der Reduktion unterliegt, seine Konzentration anfangs zwar etwa dieselbe Höhe erreicht wie bei den bisherigen Versuchen, nach einiger Zeit aber wieder sinkt und bei einem niedrigeren Betrage konstant wird.

Diese Erscheinung findet ihre Erklärung darin, dals mit dauernder Elektrolyse mehr und mehr Kalkhydrat sich ausscheidet und man es thatsächlich mit einer Lösung zu thun hat, die mehr und mehr sauer wird. Die Säure aber bewirkt einmal einen schnelleren Übergang des Hypochlorits in Chlorat, indem auch in Schichten, die der Anode ferner liegen, freie unterchlorige Säure auftritt; andererseits kann aber auch die bei der Bethätigung des letzteren auftretende Salzsäure mit noch vorhandenen Hypochlorit im Sinne der Gleichung $\mathrm{HClO}+\mathrm{HCl}=\mathrm{H}_{2} \mathrm{O}+\mathrm{Cl}_{2}$ freies Chlor geben. Deshalb beobachtet man auch, dafs der bei länger fortgesetztem Versuche beobachtete Rückgang der Hypochloritkonzentration stets mit einem Entweichen kleiner Mengen gasförmigen Chlors Hand in Hand geht. Mit fallender Hypochloritkonzentration sinken nun auch Reduktion und Sauerstoffentwickelung, und gerade diese Kurven bestätigen aufs beste wieder den engen Zusammenhang zwischen Hypochloritkonzentration und Sauerstoffentwickelung.

Auf die Entstehung eines die Reduktion des Hypochlorits beeinträchtigenden Kalkdiaphragmas dürfte auch wohl die Wirksamkeit des von KELLNER ${ }^{1}$ angewandten Zusatzes von Kalkhydrat zurückzuführen sein. Auch dieses Verfahren wurde in der wiederholt erwähnten Weise einer genauen Prüfung unterzogen.

Die in der Patentrorschrift als wesentlich gekennzeichnete Bewegung des Elektrolyten wurde bei den folgenden Versuchen durch einen Strom von Wasserstoffgas bewerkstelligt, der 2 Minuten vor der Entnahme der Gasproben abgestellt wurde.

Die Stromstärke betrug $4.5 \mathrm{Amp}$.

1 D.R.P. 90060. 
Versuch 20.1

Temperatur $8-12^{\circ} \mathrm{C}$.

Die Lösung $(500 \mathrm{ccm})$ enthielt $30 \mathrm{~g} \mathrm{NaCl}$ in $100 \mathrm{ccm}$ $+2 \% \mathrm{Ca}(\mathrm{OH})_{2}$.

$D_{K}=0.18 \mathrm{Amp} . / \mathrm{qcm} . D_{a}=0.075 \mathrm{Amp} . / \mathrm{qcm}$.

Spannung 4.5-5.3 Volt.

\begin{tabular}{|c|c|c|c|c|c|}
\hline \multirow{2}{*}{$\begin{array}{l}\text { Versuchs- } \\
\text { dauer } \\
\text { Stunden }\end{array}$} & \multirow{2}{*}{$\begin{array}{c}\text { Strom- } \\
\text { ausbeute } \\
\%\end{array}$} & \multirow{2}{*}{$\begin{array}{c}\text { Reduktion } \\
\%\end{array}$} & \multirow{2}{*}{$\begin{array}{c}\text { Sauerstoff- } \\
\text { entwickelung } \\
\% \\
\end{array}$} & \multicolumn{2}{|c|}{$\begin{array}{c}\text { Aktiv. Sauerstoff in } 500 \mathrm{ccm} \\
\text { als }\end{array}$} \\
\hline & & & & $\begin{array}{l}\text { Hypochlorit } \\
\mathrm{g}\end{array}$ & $\begin{array}{l}\text { Chlorat } \\
\text { g }\end{array}$ \\
\hline $1 / 4$ & - & - & - & 0.26 & 0.00 \\
\hline $1 / 2$ & 76.5 & 20.8 & 2.7 & - & - \\
\hline${ }^{3 / 4}$ & $\overline{6}$ & - & - & 0.63 & 0.00 \\
\hline 1 & 67.4 & 27.7 & 4.9 & - & - \\
\hline $11 / 4$ & - & - & - & 1.24 & 0.08 \\
\hline $31 / 2$ & 46.4 & 43.1 & 11.5 & 2.45 & 0.79 \\
\hline $41 / 2$ & - & 40.8 & - & 2.52 & 1.30 \\
\hline $\begin{array}{l}51 / 4 \\
71 / 2\end{array}$ & $4 \overline{2.3}$ & $\overline{40.8}$ & $\overrightarrow{17.0}$ & $\begin{array}{l}2.54 \\
2.65\end{array}$ & $\overline{2} \overline{97}$ \\
\hline & & & & & \\
\hline
\end{tabular}

Im Voltameter niedergeschlagen $42.15 \mathrm{~g} \mathrm{Ca}=10.64 \mathrm{~g}$ Sauerstoff. Die Lauge enthielt wirksamen Sauerstoff $5.542 \mathrm{~g}=52 \%$ Stromausbeute.

Versuch 21.

Temperatur $50^{\circ} \mathrm{C}$.

Die Lösung $(500 \mathrm{ccm})$ enthielt $30 \mathrm{~g} \mathrm{NaCl}$ in $100 \mathrm{ccm}$ $+2 \% \mathrm{Ca}(\mathrm{OH})_{2}$. $D_{K}=0.18$ Amp. $/ \mathrm{qcm} . D_{a}=0.075$ Amp. $/ \mathrm{qcm}$. Spannung 3.75-4.25 Volt.

\begin{tabular}{|c|c|c|c|c|c|}
\hline \multirow{2}{*}{$\begin{array}{l}\text { Versuchs- } \\
\text { dauer } \\
\text { Stunden }\end{array}$} & \multirow{2}{*}{$\begin{array}{c}\text { Strom- } \\
\text { ausbeute } \\
\% \\
\%\end{array}$} & \multirow{2}{*}{$\begin{array}{c}\text { Reduktion } \\
\%\end{array}$} & \multirow{2}{*}{$\begin{array}{c}\text { Sauerstoff- } \\
\text { entwickelung } \\
\%\end{array}$} & \multicolumn{2}{|c|}{$\begin{array}{c}\text { Aktiv. Sauerstoff in } 500 \mathrm{ccm} \\
\text { als }\end{array}$} \\
\hline & & & & $\begin{array}{c}\text { Hypochlorit } \\
\mathrm{g}\end{array}$ & $\begin{array}{c}\text { Chlorat } \\
\mathrm{g}\end{array}$ \\
\hline $1 / 4$ & - & - & - & 0.18 & 0.00 \\
\hline $1 / 8$ & 67.1 & 26.5 & 6.4 & - & - \\
\hline${ }^{3 / 4}$ & 597 & 9 & -1 & 0.39 & 0.31 \\
\hline 1 & 59.7 & 31.2 & 9.1 & - & - \\
\hline $11 / 2$ & - & - & - & 1.06 & 0.33 \\
\hline 2 & 53.7 & 31.6 & 14.7 & 1.27 & 0.48 \\
\hline 4 & 47.8 & 29.4 & 22.8 & 1.45 & 1.52 \\
\hline 5 & 50.6 & 29.1 & 20.3 & 1.54 & 2.32 \\
\hline $5^{3} / 4$ & - & - & - & 1.54 & 2.74 \\
\hline
\end{tabular}

Im Voltameter niedergeschlagen $31.47 \mathrm{~g} \mathrm{Cu}=7.94 \mathrm{~g}$ Sauerstoff. Die Lauge enthielt wirksamen Sauerstoff $4.297 \mathrm{~g}=54.1 \%$ Stromausbeute.

I Apparat wie bei Versuch 1. 
In der That hat man hier die gesteigerte Ausbeute dem Kalk zu verdanken, nicht aber wie KELLNER angiebt, wegen der Fähigkeit desselben, dem Elektrolyten eine geringe Alkalität zu erteilen, sondern in erster Linie deshalb, weil er sich an der Kathode abscheidet und dort vor Reduktion schützt. Wenn thatsächlich die durch den Kalkzusatz bedingte geringe Alkalität einen merkbaren Einflufs auf die Verhältnisse gegenüber neutralen Chloridlösungen ausübte, dann könnte, wie die später folgenden Versuche in alkalischen Lösungen darthun werden, die Hypochloritkonzentration in Versuch 21 nicht grölser sein, als sie bei Versuch 2 beobachtet wurde.

Soll man überhaupt nach der Vorschrift des KeLLneR'schen Patentes zu einigermafsen annehmbaren Resultaten gelangen, dann wird es nötig sein, in gewissen Zeitabständen frischen Kalk zuzusetzen. Denn der Kalk, der sich an der Kathode absetzt, bröckelt ab und befindet sich in einer so schwer löslichen Form, dals auch ein fleifsiges Umrühren wenig oder nichts zu seiner Lösung beiträgt.

Für die Richtigkeit der entwickelten Ansicht ist nun ferner beweisend nicht nur der Wert der Sauerstoffentwickelung, der immer ansteigt, wenn man die Reduktion vermindert - er liefse sich auch durch die geringe Alkalität erklären —, sondern vor allen Dingen der Umstand, dafs man zu demselben Ziele gelangt, ja dafs man weit bessere Ausbeuten erreicht, wenn man dem Elektrolyten anstatt Calciumhydrat Calciumchlorid zusetzt. Dieses wirkt besonders dadurch der Chloratbildung günstig, dals es als leicht lösliches Salz gestattet, die Konzentration der Calciumionen in der Lösung so zu vermehren, dais sie reichlicher als bei Zusatz des schwer löslichen Kalkhydrats an den kathodischen Entladungsvorgängen teilnehmen und dadurch die Abscheidung des Kalkdiaphragmas erleichtern.

Allerdings würde auch hier durch den in unlöslicher Form ausfallenden Kalk der Elektrolyt allmählich an Calciumionen verarmen, während gleichzeitig an der Anode freies Chlor auftritt, ${ }^{1}$ aber dem läfst sich leicht durch einen Kunstgriff, den schon $\mathrm{FoGH}^{2}$ anwendete, abhelfen, indem man den Elektroden eine horizontale Lage giebt und zwar so, dafs sich die Anode unter der Kathode auf dem Boden der Zersetzungszelle befindet. Der von der Kathode

1 Vergl. Oetreu, Zeitschr. Elektrochem. 5, 1.

${ }^{2}$ Inaugural-Dissertation, Jena 1889 (Druck von B. G. Teubner, Dresden). 
abbröckelnde Kalk fällt dann auf die Anode und verhindert so, indem er selbst sich wieder löst, einen zu starken Überschufs an freiem Chlor.

Durch Umrühren beugt man hier zweckmälsig einer übermälsigen Anhäufung von Hypochlorit an der Anode vor.

Wie hoch man in der angedeuteten Weise die Ausbeute treiben kann, soll der folgende Versuch zeigen.

Es diente zu demselben der in Fig. 11 gezeichnete Apparat, der ohne weiteres rerständlich sein dürfte.

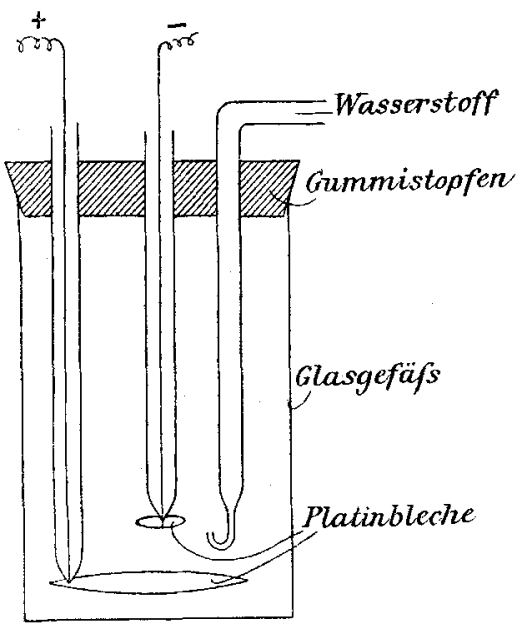

Fig. 11.

In der Figur ist eine zur Gasentnahme in den Stopfen eingesetzte Röhre nicht gezeichnet. Die Zelle falste ca. $550 \mathrm{ccm}$ Flüssigkeit. Die Anode bestand aus einem muldenförmigen Platinblech mit ca. $30 \mathrm{qcm}$ einseitig wirksamer Oberfläche, die Kathode aus einem runden Platinblech, mit ca. $7 \mathrm{qcm}$ einseitiger Oberfläche. Beide Elektroden waren horizontal und parallel $\mathrm{zu}$ einander in $2 \mathrm{~cm}$ Entfernung angebracht.

Die Durchmischung der Flüssigkeit geschah durch einen langsamen Wasserstoffstrom. 


\section{Versuch 22.}

Temperatur $50^{\circ} \mathrm{C}$.

Die Lösung $(500 \mathrm{ccm})$ enthielt $30 \mathrm{~g} \mathrm{NaCl}$ in $100 \mathrm{ccm}+5 \mathrm{~g} \mathrm{CaCl}_{\mathbf{q}}+6$ aq. $D_{K}=0.64 \mathrm{Amp} \cdot / \mathrm{qcm} . D_{a}=0.15 \mathrm{Amp} . / \mathrm{qcm}$.

Spannung 5.5-6.0 Volt.

\begin{tabular}{c|c|c|c}
\hline \hline $\begin{array}{c}\text { Versuchs- } \\
\text { dauer } \\
\text { Stunden }\end{array}$ & $\begin{array}{c}\text { Strom- } \\
\text { ausbeute } \\
\%\end{array}$ & $\begin{array}{c}\text { Reduktion } \\
\%\end{array}$ & $\begin{array}{c}\text { Sauerstoff- } \\
\text { entwickelung } \\
\%\end{array}$ \\
\hline \hline & & & \\
$1 / 4$ & 89.9 & 8.7 & 1.4 \\
$11 / 2$ & 78.5 & 13.8 & 8.7 \\
3 & 78.1 & 13.8 & 8.1 \\
18 & 86.3 & 12.8 & 6.9 \\
20 & 84.4 & 9.3 & 4.7 \\
& & 11.1 & 4.5
\end{tabular}

Im Voltameter niedergeschlagen $97.6 \mathrm{~g} \mathrm{Cu}=24.6 \mathrm{~g}$ Sauerstoff. Die Lauge enthielt wirksamen Sauerstoff $20.88 \mathrm{~g}=84.8 \%$ Stromausbeute.

Ob diesem Verfahren eine technische Bedeutung beizumessen ist, ist sehr zweifelhaft. Als ungünstig tritt der Umstand in den Vordergrund, dals man die Anode, die aus Platin gefertigt sein mufs, nur einseitig ausnutzen kann. Man würde also auf eine bestimmte Zahl von Zersetzungszellen doppelt soviel Platin verwenden müssen, wie bei vertikal gestellten Elektroden.

Aufserdem dürfte es beim Übersetzen in den Grofsbetrieb einige Schwierigkeiten bereiten, eine geeignete Zuleitung bez. eine passende Isolierung für die am Boden der Zelle anzubringende Elektrode zu finden.

Man kann aber den Vorteil, den ein Chlorcalciumzusatz bietet, noch einfacher dadurch sich zu Nutze machen, dafs man ohne Vergröfserung der Elektroden und ohne die Stromstärke zu verändern, ein möglichst grofses Lösungsvolumen anwendet. Bewegt man dabei den Elektrolyten fleilsig, so wird der Sättigungspunkt der Flüssigkeit für Chlor einerseits später erreicht und andererseits findet das in schwer löslicher Form abgeschiedene Kalkhydrat doch Gelegenheit, sich wieder zu lösen, da es auf grölserem Raum mit Chlor und unterchloriger Säure zusammentreffen kann.

3 Liter einer Lösung, welche $25 \mathrm{~g}$ Chlornatrium und $2.5 \mathrm{~g}$ Chlorcalcium in $100 \mathrm{ccm}$ enthielt, wurden bei $45-50^{\circ} \mathrm{C}$. mit 5 Amp. $\left[\mathrm{D}_{K}=0.18 \mathrm{D}_{a}=0.075 \mathrm{Amp} / \mathrm{q} \mathrm{cm}\right] 6$ Tage und 6 Nächte elektrolysiert, während sie durch ein MrLIUs-Fromm'sches Rührwerk bewegt wurden. 


\section{Versuch 23.}

Die Stromausbeuten betrugen:

$\begin{array}{rrr}\text { Nach } 24 & \text { Stunden } 80 \% \\ 48 & , & \mathbf{7 9} " \\ 96 & " & \mathbf{7 4} " \\ 120 & 7 & \mathbf{7 2} " \\ 144 & , & 70 "\end{array}$

Die Spannung belief sich auf 5.2-5.4 Volt, war also verhältnismälsig beträchtlich.

Aus diesem Versuch folgt für die Technik, dals für die elektrolytische Chloraterzeugung das Zusammenwirken von vier Faktoren wichtig ist:

1. Vermeidung der Reduktion,

2. schwache Säuerung und

3. grofses Lösungsvolumen, um diese wirksam werden zu lassen.

4. Wahl der Temperatur über $30^{\circ} \mathrm{C}$., um die sekundäre Reaktion zu beschleunigen, an Spannung zu sparen und Perchloratbildung zu vermeiden.

Schliefslich sei noch bemerkt, dafs unter Beobachtung des oben angeführten Gesichtspunktes der schwachen Säuerung die Gewinnung von Chlorat durch Elektrolyse chromathaltiger Chloridlösungen einer nutzbringenderen Verwendung fähig erscheint, wenn man während der Elektrolyse einen schwachen Strom von Kohlensäure durch den Elektrolyten leitet. Es gelang bei einem in der angedeuteten Weise durchgeführten Versuche eine dauernde Ausbeute von $71 \%$ zu erzielen, die sich möglicherweise durch zweckmälsige Anordnung noch steigern läfst.

\section{Eloktrolyse von Alkalichloridlösungen unter Zusatz von Alkalihydraten.}

Die Erscheinungen bei der Elektrolyse neutraler Alkalichloridlösungen sind im ersten Abschnitte so weit geklärt, dafs nummehr auch der zweiten, eingangs aufgeworfenen Frage näher getreten werden kann, ob die sowohl in saurer wie in neutraler und alkalischer Lösung beobachtete elektrolytische Chloratbildung ihrer Natur nach z. anorg. Chem. XXII. 
ein und derselbe Vorgang ist oder ob verschiedene, durch die wechselnden Bedingungen bald mehr, bald weniger begünstigte Vorgänge hier im Spiele sind.

\section{A. Allgemeines Gepräge des Einflusses eines Alkalizusatzes auf die Elektrolyse von Alkalichloridlösungen.}

Über den Einflufs, welchen ein wechselnder Zusatz freien Alkalihydrats auf die Elektrolyse von Alkalichloridlösungen ausübt, liegen zwei Experimentaluntersuchungen vor, die eine von Oetres, ${ }^{1}$ die andere von WoHLwiLu. ${ }^{2}$ Das wichtigste Ergebnis der ersteren, welches ganz besonders geeignet erscheint, die fraglichen Vorgänge zu kennzeichnen, darf darin erblickt werden, dafs eine Lösung von Chlorkalium $(20 \mathrm{~g}$ in $100 \mathrm{ccm}$ Wasser) nach Zusatz von $0.3 \mathrm{~g} \mathrm{KOH}$ auf $100 \mathrm{ccm}$ bei der Elektrolyse sich nicht wesentlich anders verbält, als eine neutrale, während bei einer Erhöhung des Alkaligehaltes auf $1 \mathrm{~g} \mathrm{KOH}$ auf $100 \mathrm{ccm}$ der Hypochloritgehalt der Lösung schon sehr stark zurücktritt und bei $2 \mathrm{~g} \mathrm{KOH}$ auf $100 \mathrm{ccm}$ so gering ist, dafs von Anfang an das Chlorat als nahezu einziges Produkt der Elektrolyse bezeichnet werden kann.

Macht man zunächst die Annahme, dals auch in alkalischer Lösung ebenso wie in neutraler das Chlorat wesentlich durch sekundäre Umwandlung anfänglich gebildeten Hypochlorits entstanden ist, so könnten die eben citierten Beobachtungen OETTEL's auf folgendem Wege eine Deutung finden.

$\mathrm{Zu}$ Beginn der Elektrolyse wird Hydroxyl neben Chlor entladen; letzteres tritt aber alsbald mit benachbartem Hydroxyl in Wechselwirkung unter Bildung von Hypochlorit. Dieses Salz wird in um so grölserer Konzentration an der Anode auftreten, je höher der Alkaligehalt der Lösung ist. Um so lebhafter wird es aber auch an der Elektrolyse teilnehmen und unterchlorige Säure bilden, die dann auf verhältnismälsig konzentriertes Hypochlorit trifft und dieses weitgehend in Chlorat verwandeln kann, bevor es aus der nächsten Nähe der Anode sich entfernt und sich in der ganzen Flüssigkeit verteilt. Es wird also auf Kosten von Hypochlorit mit zunehmender Alkalität der Lösung die Chloratbildung in immer gröfserem Umfange vor sich gehen.

1 a. a. 0 .

${ }^{2}$ Zeitsehr. Elektrochem. 5, Heft 5. 
Der im ersten Teile angeführte Versuch 3 zeigte, dals beim Ubergang von einer neutralen zu einer $0.1 \%$ Natronhydrat enthaltenden Natriumchloridlösung eine Abnahme des schliefslich konstanten Hypochloritgehaltes und eine schnellere Zunahme des Chlorats stattfand. Bei weiterem Steigern der Alkalität auf $0.3 \mathrm{~g}$ $\mathrm{NaOH}$ in $100 \mathrm{ccm}$ einer konzentrierten Chlornatriumlösung wurde an gekühlter Anode ebenso wie in neutraler Lösung bei einer Stromdichte von $\mathrm{D}_{a}=0.04 \mathrm{Amp} . / \mathrm{cm}$ das Auftreten von festem Chlorhydrat beobachtet; es war also auch in diesem Falle in unmittelbarer Nähe der Anode kein freies Alkali mehr anzunehmen.

Danach darf man bei so geringem Alkaligehalt des Elektrolyten ohne weiteres zu einer ähnlichen Deutung der Erscheinungen greifen wie für neutrale Lösungen.

Von vornherein nicht ohne Bedenken aber wird eine solche einheitliche Auffassung, wenn man sie auch auf stärker alkalische Chloridlösungen ausdehnen will, die in Bezug auf freies Alkali einhalb bis doppelt normal sind.

Es erscheint fraglich, ob es erlaubt ist, anzunehmen, dals, selbst wenn unterchlorige Säure an der Anode entsteht, diese eine genügende Zeit in freiem Zustande bleibt, um ihre oxydierende Wirkung ausüben zu können, bevor sie von dem Alkali der Lösung neutralisiert wird. Hierüber sollen die folgenden Versuche Aufschlufs geben, bei denen wie bei Versuch 4 eine ähnlich konzentrierte Lösung von Natriumhypochlorit in einer besonderen Anodenzelle der Elektrolyse unterworfen wurde, nur mit dem Unterschiede, dals die Lösung hier alkalisch und zwar in Bezug auf freies Natronhydrat normal war. Um diese Alkalität während der Elektrolyse annähernd auf derselben Stärke zu erhalten, wurden von Zeit zu Zeit kleine Mengen Alkali zum Ersatz des verschwundenen binzugefügt.

Es wurde bei zwei Temperaturen, bei $15-18^{\circ}$ und bei $55^{\circ}$ gearbeitet, da OEтTEL ${ }^{1}$ sehr interessante Einflüsse der Temperatur bei seinen Untersuchungen in alkalischer Lösung beobachtet hatte.

Die anodische Stromdichte betrug bei Versuch 24 und 25 $0.05 \mathrm{Amp} / \mathrm{qcm}$, bei Versuch $260.16 \mathrm{Amp} . / \mathrm{qcm}$, so dafs bei letzterem der Anodenraum von innen heraus gekühlt werden mufste.

1 a. a. 0 . 


\section{Versuch 24.}

Die Stromstärke betrug $1 \mathrm{Amp}$. Temperatur $15-18^{\circ} \mathrm{C}$.

Die Lösung der Anodenthonzelle (50 ccm) enthielt:

$\left.\begin{array}{ccc}\text { wirksamen Sauerstoff als Hypochlorit } & 0.598 \mathrm{~g} \\ , & \text { "Chlorat } & 0.035, ",\end{array}\right\}+4 \% \mathrm{NaOH}$.

$$
\mathrm{D}_{K}=0.05 \mathrm{Amp} . / \mathrm{qcm} . \mathrm{D}_{a}=0.05 \mathrm{Amp} . / \mathrm{qm} \text {. }
$$

Spannung 4.4-4.6 Volt. Dauer der Elektrolyse 60 Min.

\begin{tabular}{l|c|c|c}
\hline $\begin{array}{c}\text { Aktiver } \\
\text { Sauerstoff } \\
\text { als }\end{array}$ & $\begin{array}{c}\text { Vor der } \\
\text { Elektrolyse } \\
\mathrm{g}\end{array}$ & $\begin{array}{c}\text { Nach der } \\
\text { Elektrolyse } \\
\mathrm{g}\end{array}$ & $\begin{array}{c}\text { Differenz } \\
\mathrm{g}\end{array}$ \\
\hline & & & \\
Hypochlorit & 0.598 & 0.444 & 0.154 \\
Chlorat & 0.035 & 0.303 & 0.268 \\
Gesamt & 0.633 & 0.747 & 0.114
\end{tabular}

Im Voltameter niedergeschlagen $1.156 \mathrm{~g} \mathrm{Cu}=0.2917 \mathrm{~g}$ Sauerstoff $=39.3^{\circ} \%$ Stromausbeute an hinzugekommenem aktiven Sauerstoff.

Die Zunahme des Gesamtsauerstoffes von $0.11487 \mathrm{~g}$ bedingt gemäls der Gleichung $\overline{\mathrm{ClO}}+2 \mathrm{O}=\overline{\mathrm{ClO}} \mathrm{O}_{3}$ eine Abnahme des Hypochloritsauerstoffes von $0.05743 \mathrm{~g}$; folglich sind verschwunden

$$
0.05743 \mathrm{~g} \text { Hypochloritsauerstoff oder } 37.3 \%
$$

durch direkte Oxydation,

durch sekundäre Umwandlung.

$$
0.09666 \mathrm{~g} \text { oder } 62.7 \%
$$

\section{Versuch 25.}

Die Stromstärke betrug 1 Amp. Temperatur $55^{\circ} \mathrm{C}$.

Die Lösung in der Anodenthonzelle (50 ccm) enthielt:

$\left.\begin{array}{ccc}\text { wirksamen Sauerstoff als Hypochlorit } 0.538 \mathrm{~g} \\ ,, \quad \text { " Chlorat } & 0.012,\end{array}\right\}+4 \% \mathrm{NaOH}$.

$\mathrm{D}_{K}=0.05 \mathrm{Amp} . / \mathrm{qcm} . \mathrm{D}_{\alpha}=0.05 \mathrm{Amp} . / \mathrm{qcm}$.

Spannung 3.1-3.3 Volt. Dauer der Elektrolyse 45 Min.

\begin{tabular}{l|c|c|c}
\hline $\begin{array}{c}\text { Aktiver } \\
\text { Sauerstoff } \\
\text { als }\end{array}$ & $\begin{array}{c}\text { Vor der } \\
\text { Elektrolyse } \\
\mathrm{g}\end{array}$ & $\begin{array}{c}\text { Nach der } \\
\text { Elektrolyse } \\
\mathrm{g}\end{array}$ & Differenz \\
\hline & $\mathrm{g}$ & $\mathrm{g}$ \\
\hline & 0.538 & 0.384 & 0.154 \\
Hypochlorit & 0.012 & 0.177 & 0.165 \\
Gesamt & 0.550 & 0.561 & 0.011
\end{tabular}

Im Voltameter viedergeschlagen $0.91 \mathrm{~g} \mathrm{Cu}=0.2297 \mathrm{~g}$ Sauerstoff $=4.8 \%$ Stromausbente an hinzugekommenem aktiven Sauerstoff. 
Die Zunahme des Gesamtsauerstoffes von $0.011 \mathrm{~g}$ bedingt eine Abnahme des Hypochloritsauerstoffes von $0.0055 \mathrm{~g}$; folglich sind verschwunden

$0.0055 \mathrm{~g}$ Hypochloritsauerstoff oder $3.6 \%$

durch direkte Oxydation,

$$
0.1485 \mathrm{~g} \text { oder } 96.4 \%
$$

durch sekundäre Umwandlung.

\section{Versuch 26.}

Die Stromstärke betrug 1 Amp. Temperatur $15-18^{\circ} \mathrm{C}$.

Die Lösung im Anodenraum (50 ccm) enthielt:

$\left.\begin{array}{ccc}\text { wirksamen Sauerstoff als Hypochlorit } 0.580 \mathrm{~g} \\ , \quad " \text { Chlorat } & 0.005, "\end{array}\right\}+4 \% \mathrm{NaOH}$.

$\mathrm{D}_{K}=0.05$ Amp. $/ \mathrm{qcm} . \mathrm{D}_{a}=0.16 \mathrm{Amp} . / \mathrm{qm}$.

Spannung 5.5 Volt. Dauer der Elektrolyse 45 Min.

\begin{tabular}{l|c|c|c}
\hline $\begin{array}{c}\text { Aktiver } \\
\text { Sauerstoff } \\
\text { als }\end{array}$ & $\begin{array}{c}\text { Vor der } \\
\text { Elektrolyse } \\
\mathrm{g}\end{array}$ & $\begin{array}{c}\text { Nach der } \\
\text { Elektrolyse } \\
\mathrm{g}\end{array}$ & $\begin{array}{c}\text { Differenz } \\
\mathrm{g}\end{array}$ \\
\hline & & & \\
Hypochlorit & 0.580 & 0.424 & 0.156 \\
Chlorat & 0.005 & 0.232 & 0.227 \\
Gesamt & 0.585 & 0.656 & 0.071
\end{tabular}

Im Voltameter niedergeschlagen $0.88 \mathrm{~g} \mathrm{Cu}=0.22138 \mathrm{~g}$ Sanerstoff $=32.3^{\circ} \%$ Stromausbeute an hinzugekommenem aktiven Sauerstoff.

Die Zunahme des Gesamtsauerstoffes von $0.0716 \mathrm{~g}$ bedingt eine Abnahme des Hypochloritsauerstoffes von $0.0358 \mathrm{~g}$.

Mithin sind durch direkte Oxydation verschwunden durch sekundäre Oxydation

$$
0.0358 \mathrm{~g} \text { Hypochloritsauerstoff oder } 23 \% \text {, }
$$

$$
0.1202 \mathrm{~g} \text { oder } 77 \% \text {. }
$$

Zum Vergleich seien die Ergebnisse der mit gleicher Stromdichte vorgenommenen Versuche 4,24 und 25 in der folgenden

\begin{tabular}{|c|c|c|c|}
\hline \multirow[t]{2}{*}{$\begin{array}{c}\text { Auf } 100 \text { Teile ursprünglichen } \\
\text { Hypochloritsauerstotts waren nach } \\
\text { einstündiger Elektrolyse }\end{array}$} & \multirow{2}{*}{ 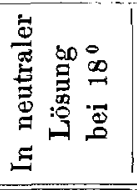 } & \multicolumn{2}{|c|}{$\begin{array}{l}\text { In } 1 / 1 \text {-normal- } \\
\text { alkalischer } \\
\text { Lösung bei }\end{array}$} \\
\hline & & $18^{\circ}$ & $55^{\circ}$ \\
\hline Als Hypochloritsauerstoff noch vorhanden & 44.9 & 74.3 & 38.1 \\
\hline In Chloratsauerstoff übergegangen. . . . & 55.1 & 25.7 & 61.9 \\
\hline Durch primäre Oxydation hinzugekommen. & 12.4 & 19.2 & 2.8 \\
\hline
\end{tabular}
Übersicht zusammengestellt.

Übersicht 1 . 
Die Versuche 24, 25 und 26 bringen das interessante Ergebnis, dals selbst bei Gegenwart reichlichen Alkalis Hypochlorit anodisch auf sekundärem Wege Chlorat bilden kann, dafs also selbst in normal alkalischen Lösungen freie unterchlorige Säure an der Anode in erheblichem Umfange ihre oxydierende Wirkung entfalten kann, ehe sie der Neutralisation unterliegt.

Bei $55^{0}$ ist die Geschwindigkeit der sekundären Umwandlung von Hypochlorit in Chlorat so grofs, dafs diese Betbätigung der freien unterchlorigen Säure noch einen grölseren Umfang annimmt, als in neutralen Lösungen bei gewöhnlicher Temperatur.

Eine Erhöhung der Stromdichte auf das Dreifache übt auf 'diese sekundäre Chloratbildung nur eine geringfügige Änderung aus in dem Sinne, dafs dadurch das Auftreten freier unterchloriger Säure in grölserer Konzentration unmittelbar an der Anode hervorgerufen wird.

Wie zu erwarten stand, tritt hier ebenso wie in neutraler Hypochloritlösung eine direkte Oxydation des Hypochlorits ein, welche bei gewöhnlicher Temperatur sogar hier stärker ist als dort. $\mathrm{Ob}$ dies aber auf einer besonderen Wirkung des Alkalis beruht, oder aber darauf, dafs in alkaiischer Lösung mehr Hypochlorit erhalten bleibt und deshalb auch reichlicher von anodischem Sauerstoff oxydiert werden kann, muls dahingestellt bleiben. Jedenfalls wird durch erböhte Temperatur diese direkte Oxydation stark in den Hintergrund gedrängt.

Diese Versuche weisen auf das hin, was wir bei der Elektrolyse alkalischer Chloridlösungen zu erwarten haben, wenn wir annehmen, dals bei ihnen das Chlorat im wesentlichen sekundär aus dem Hypochlorit sich bildet.

Einmal mülste bei stärkerem Alkaligehalt das in schwächer alkalischen Lösungen verschwindende Hypochlorit wieder gegenüber dem Chlorat hervortreten und dann mülste bei gleichem Alkaligehalt wie in neutralen Lösungen mit steigender Temperatur der Hypochloritgehalt sinken.

Diese beiden Punkte waren experimentell zu prüfen durch Untersuchung der Hypochlorit- und Chloratmengen, die bei gegebener Stromdichte entstehen, wenn 1. der Alkaligehalt und 2. die Temperatur geändert wird. 
Die entsprechenden Versuche OETtEI's gaben keine genügende Antwort auf die beregte Frage, so dafs eigene Versuche nötig waren.

Bei denselben wurde besonders Wert darauf gelegt, die an der Anode herrschende Temperatur genau regulieren und die kathodische Reduktion auf ein Minimum einschränken zu können. Daher wurde folgende Versuchsanordnung gewählt.

Als Anode diente eine grolse Platinschale, die bei den Versuchen in der Kälte in eine Mischung von Eis und Kochsalz gesetzt und mit dem Elektrolyten gefüllt wurde. Als Kathode wurde ein Platintiegel verwendet, der nur mit seinem Boden in die Flüssigkeit eintauchte und, wie aus der Zeichnung ersichtlich, so eingerichtet war, dafs er mit Leitungswasser, das durch die Kältemischung temperiert war, gekühlt werden konnte. Die Temperatur des Elektrolyten kann bei dieser Anordnung selbst bei hohen Stromdichten lange Zeit unter $8^{\circ} \mathrm{C}$. gehalten werden.

Zur Elektrolyse kamen $200 \mathrm{ccm}$ Lösung, die eine Oberfläche der Platinschale von rund $100 \mathrm{qcm}$ bespülten. Der Boden des Platintiegels hatte eine Oberfläche von ca. $3.5 \mathrm{qcm}$. Die Stromstärke betrug 4 Ampère. Sollte bei einer erheblich über $0^{0}$ liegenden Temperatur gearbeitet werden, so wurde die Schale in ein Wasserbad von der gewünschten Temperatur eingesetzt und der Platintiegel leer gelassen.

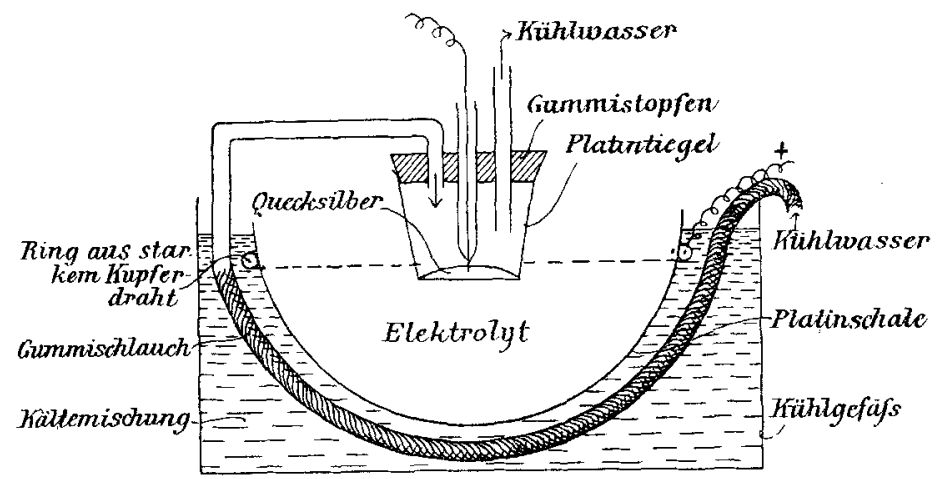

Fig. 12. 
Versuch 27.

Die Stromstärke betrug 4 Amp. Temperatur $6-8^{\circ}$.

Die Lösung (200 ccm) enthielt:

$20 \mathrm{~g} \mathrm{NaCl}$ in $100 \mathrm{cem}$.

$\mathrm{D}_{K}=1.14 \mathrm{Amp} / \mathrm{qcm} . \mathrm{D}_{a}=0.04 \mathrm{Amp} \cdot / \mathrm{qcm}$.

Spanuung 9.5-10 Volt. Dauer der Elektrolyse 60 Min.

\begin{tabular}{|c|c|c|c|c|c|}
\hline $\begin{array}{l}\mathrm{NaOH} \\
\text { in }\end{array}$ & \multicolumn{2}{|c|}{$\begin{array}{c}\text { Aktiver Sauerstoff } \\
\text { als }\end{array}$} & $\begin{array}{c}\text { Im Voltameter } \\
\text { nieder- }\end{array}$ & $\begin{array}{l}\text { Dem Cu ent- } \\
\text { sprechender }\end{array}$ & Strom- \\
\hline $100 \mathrm{ccm}$ & Hypochlorit & Chlorat & geschlagen $\mathrm{Cu}$ & Sanerstof? & ansbeute \\
\hline$g$ & $\mathrm{~g}$ & $g$ & $g$ & $g$ & $\%$ \\
\hline 0 & 0.6860 & 0.1440 & 4.52 & 1.137 & 73.0 \\
\hline 0.3 & 0.5616 & 0.2384 & 4.36 & 1.097 & 72.9 \\
\hline 1 & 0.0888 & 0.6720 & 4.62 & 1.166 & 65.3 \\
\hline 1.5 & 0.0084 & 0.7036 & 4.66 & 1.172 & 60.8 \\
\hline 2 & 0.0034 & 0.6290 & 4.61 & 1.163 & 57.0 \\
\hline 4 & 0.0028 & 0.5530 & 4.83 & 1.219 & 45.6 \\
\hline
\end{tabular}

Einfluís der Alkalität bei 1 stïndiger Elektrolyse einer Lösung von $20 \mathrm{~g} \mathrm{NaCl}$ in $100 \mathrm{ccm}$ bei 0 bis $5^{\circ} \mathrm{C}$.

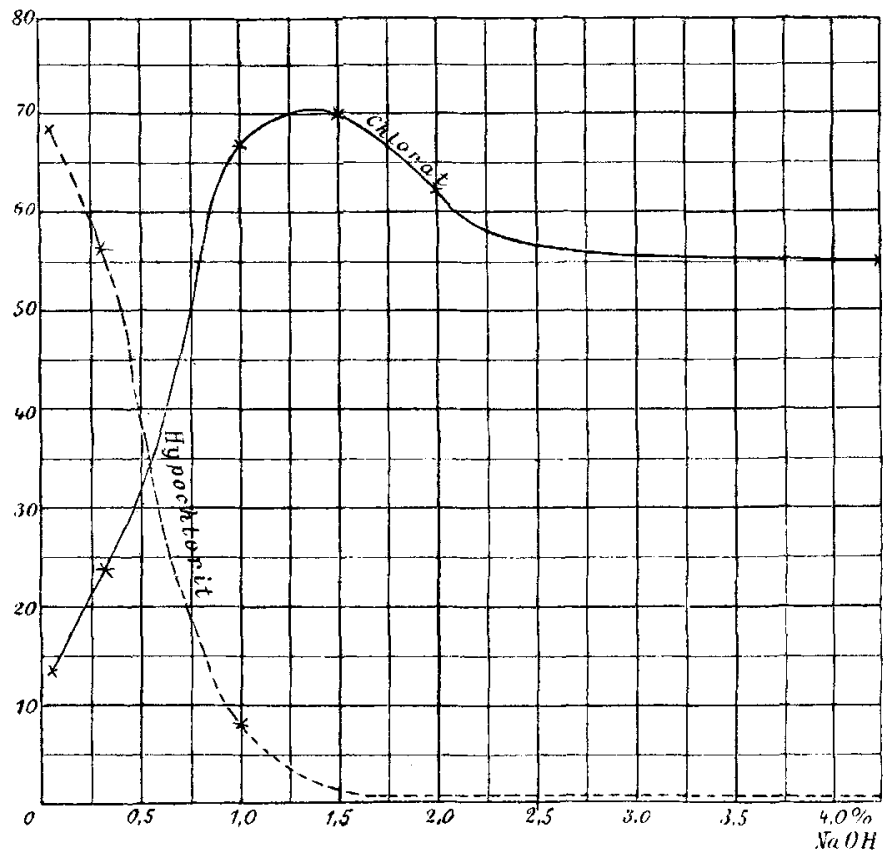

Fig. 13. 


\section{Versuch 28.}

Die Lösung $(200 \mathrm{ccm})$ enthielt:

Die Stromstärke betrug 4 Amp.

$20 \mathrm{~g} \mathrm{NaCl}$ in $100 \mathrm{~cm}+4 \% \mathrm{NaOH}$.

$\mathrm{D}_{K}=1.14 \mathrm{Amp} . / \mathrm{qcm}$. $\mathrm{D}_{a}=0.04 \mathrm{Amp} \cdot / \mathrm{q} \mathrm{cm}$.

Dauer einer jeden Elektrolyse 60 Min.

\begin{tabular}{|c|c|c|c|c|c|c|}
\hline \multirow{2}{*}{$\begin{array}{c}\text { Tempe- } \\
\text { ratur } \\
{ }^{\circ} \mathrm{C} .\end{array}$} & \multicolumn{2}{|c|}{$\begin{array}{c}\text { Aktiver Sauerstoff } \\
\text { als }\end{array}$} & \multirow{2}{*}{$\begin{array}{c}\text { Im Voltameter } \\
\text { nieder- } \\
\text { geschlagen } \mathrm{Cu} \\
\mathrm{g}\end{array}$} & \multirow{2}{*}{$\begin{array}{c}\text { Dem Ca ent- } \\
\text { sprechender } \\
\text { Sauerstoff } \\
\mathrm{g}\end{array}$} & \multirow{2}{*}{ 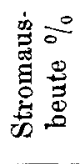 } & \multirow{2}{*}{ 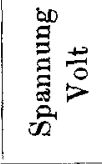 } \\
\hline & $\begin{array}{c}\text { Hypochlorit } \\
\mathrm{g}\end{array}$ & $\begin{array}{c}\text { Chlorat } \\
\mathrm{g}\end{array}$ & & & & \\
\hline $6--8$ & & & & & 45.6 & \\
\hline 30 & & & & & 34. & $.2-1$ \\
\hline 52 & & & & & 27.2 & 5 \\
\hline $76-78$ & 0.0342 & 0.1638 & 4.61 & 1.163 & 17.0 & 4.2 \\
\hline
\end{tabular}

Einflufs der Temperatur bei 1 stündiger Elektrolyse einer Lösung von $20 \mathrm{~g} \mathrm{NaCl}$ $+4 \mathrm{~g} \mathrm{NaOH}$ in $100 \mathrm{ccm}$.

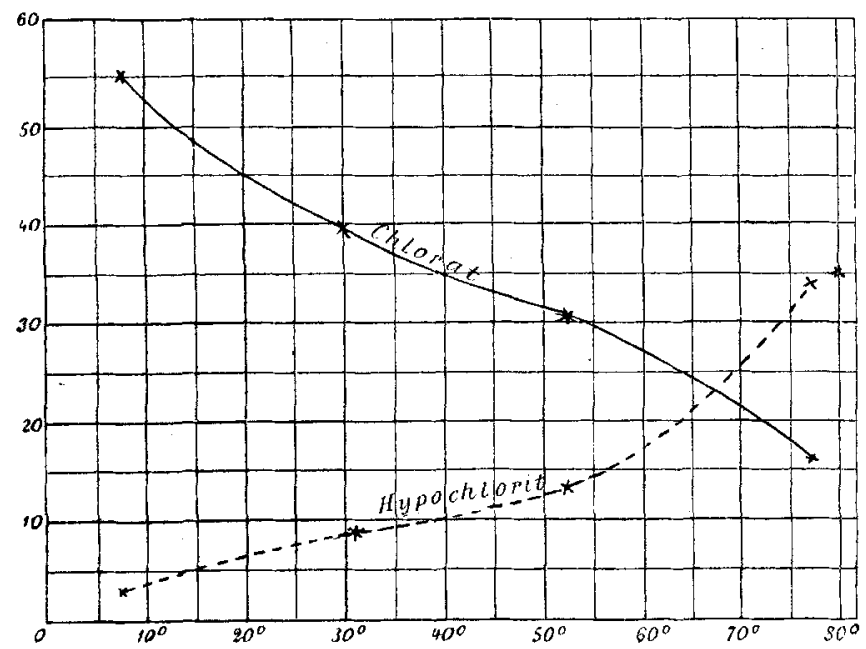

Fig. 14.

Versuch 27 zeigt, wie bei einstündiger Elektrolyse mit steigendem Alkaligehalt die Hypochloritmenge, welche sich in der Lösung vorfindet, anfangs sehr schnell sinkt, während die Chloratmenge entsprechend steigt. Überschreitet der Gehalt der Lösung an freiem 
Alkali $1 \mathrm{~g} \mathrm{NaOH}$ in $100 \mathrm{ccm}$, so nimmt das Chlorat langsamer zu und seine Menge erreicht bei $1.5 \mathrm{~g} \mathrm{NaOH}$ in $100 \mathrm{ccm}$ ein Maximum, um von da $a b$ erst schneller, dann nur ganz langsam zu sinken. Gleichzeitig erreicht das Hypochlorit bei Gegenwart von $1.5 \mathrm{~g} \mathrm{NaOH}$ in $100 \mathrm{ccm}$ einen sehr niedrigen Wert, der entgegen unserer Erwartung sich noch weiter vermindert und nicht wieder ansteigt.

Auch der Einflufs der Temperatur ist, wie Versuch 28 zeigt, bei einer $4 \mathrm{~g} \mathrm{NaOH}$ in $100 \mathrm{ccm}$ enthaltenden Lösung von Kochsalz nicht derjenige, der die sekundäre Chloratbildung kennzeichnet. Mit steigender Temperatur nimmt nämlich das Hypochlorit nicht ab, sondern $\mathrm{zu}$.

Man ist also demnach nicht berechtigt, bei der Elektrolyse stärker alkalischer Lösungen die Chloratbildung als im wesentlichen sekundär erfolgend anzusehen, wie man das, wie oben dargethan, für schwach alkalische Lösungen ohne weiteres thun darf. Die Vorgänge bei der Elektrolyse schwach saurer, neutraler oder schwach alkalischer Chloridlösungen einerseits und die bei der Elektrolyse stärker alkalischer Chloridlösungen andererseits müssen deshalb unter verschiedenen Gesichtspunkten behandelt werden.

Wenn nun aber in stärker alkalischen Lösungen die Chloratbildung nicht mehr dem Hauptbetrage nach sekundär durch Oxydation des Hypochlorits durch unterchlorige Säure erfolgt, so mul's dieser rein chemische Vorgang hier durch einen andern teilweise ersetzt werden, der elektrochemischer Natur ist.

Dieser Vorgang ist dadurch gekennzeichnet, dafs er von einem hohen Anodenpotential und von niederer Temperatur begünstigt wird, und zwar so, dafs eine hinreichende Steigerung des ersteren die Wirkung der Erhöhung der letzteren auszugleichen vermag. OETTEL fand, dals bei einer anodischen Stromdichte von 0.146 Amp./qcm bei Gegenwart von $4 \mathrm{~g} \mathrm{NaOH}$ in $100 \mathrm{ccm}$ Lösung zwischen $15^{\circ}$ und $75^{\circ}$ keine Zunahme des Hypochlorits und nur eine sebr geringe Abnahme der Stromausbeute erfolgt. Auch die Ergebnisse der folgenden Versuche zeigen, dafs der Einflufs einer Temperaturerhöhung um so stärker hervortritt, eine je niedrigere Stromdichte man verwendet, 

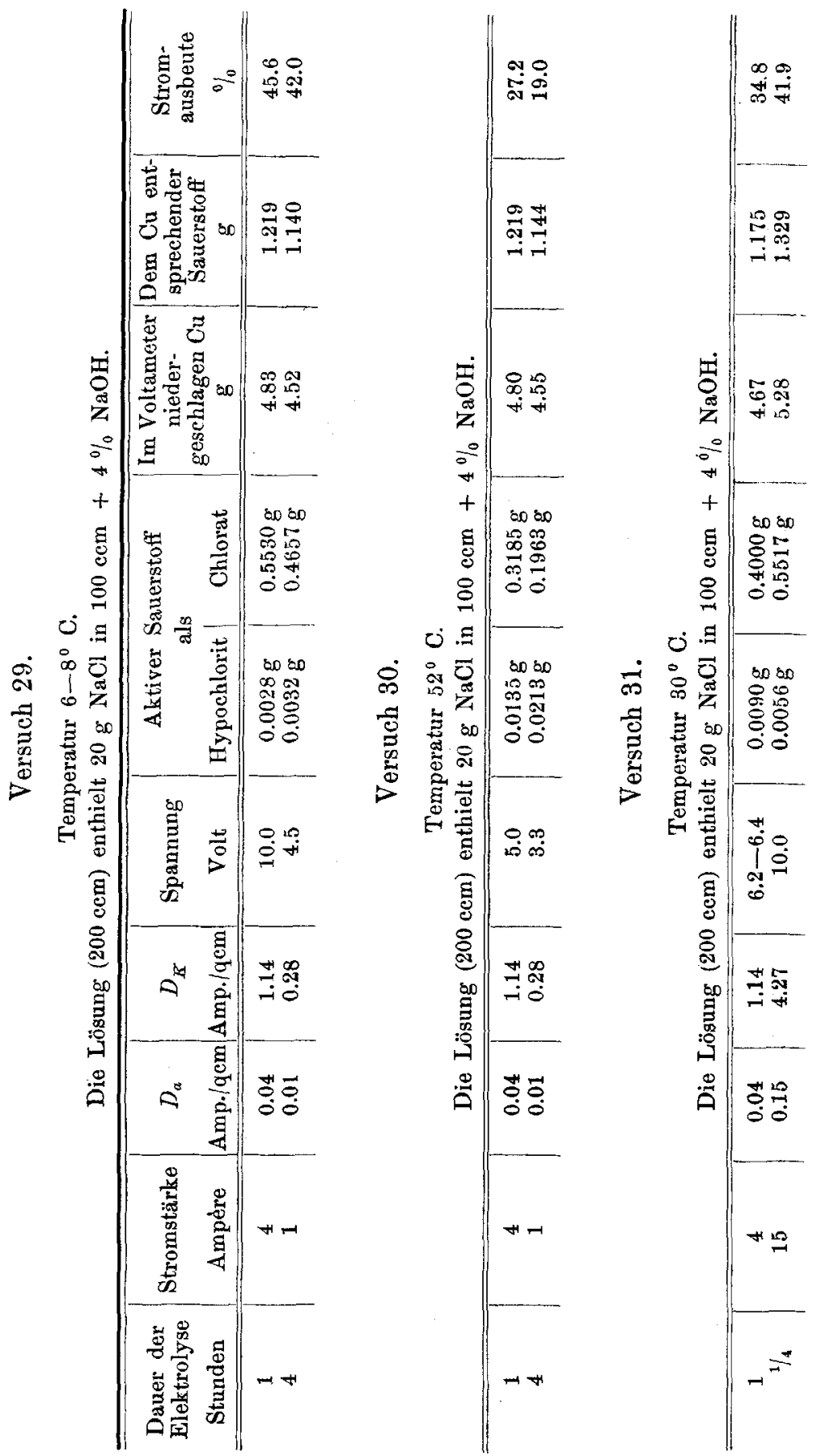


\section{B. Über einige Besonderheiten schwächer alkalischer. Alkalichloridlösungen.}

Wie oben erwähnt, darf man in schwächer alkalischen Chloridlösungen bei der Elektrolyse ähnliche anodische Vorgänge wie in neutralen Lösungen annehmen. Bis zu welchem Gehalt an Alkali eine solche Ähnlichkeit besteht, ist schwer zu sagen.

Es ist wohl sicher anzunehmen, dafs ein allmähliches Übergehen zu dem durch einen verstärkten Alkaligehalt bedingten veränderten Verhalten der Chloridlösungen stattfindet in der Weise, dals die eine Art von Vorgängen die andere verdrängt. Jedenfalls zeigt der folgende Versuch, der den Einflufs der Temperatur bei Gegenwart geringerer Alkalimengen kennzeichnet, dals ein Gehalt von $1 \mathrm{~g} \mathrm{NaOH}$ in $100 \mathrm{ccm}$ die Elektrolyse einer $20 \mathrm{~g} \mathrm{NaCl}$ in $100 \mathrm{~g}$ enthaltenden Lösung von einer neutralen nicht wesentlich verschieden erscheinen lälst.

\section{Versuch 32.}

Die Stromstärke betrug 4 Amp.

Die Lösung $(200 \mathrm{ccm}$ ) enthielt $20 \% \mathrm{NaCl}+1 \% \mathrm{NaOH}$.

$\mathrm{D}_{K}=1.14 \mathrm{Amp} . / \mathrm{qcm} . \mathrm{D}_{a}=0.04 \mathrm{Amp} . \mathrm{qcm}$.

Dauer einer jeden Elektrolyse 60 Min.

\begin{tabular}{|c|c|c|c|c|c|c|}
\hline \multirow{2}{*}{$\begin{array}{c}\text { Tempe- } \\
\text { ratur } \\
{ }^{0} \mathrm{C}\end{array}$} & \multicolumn{2}{|c|}{$\begin{array}{c}\text { Aktiver Sauerstoff } \\
\text { als }\end{array}$} & \multirow{2}{*}{$\begin{array}{l}\text { Im Voltameter } \\
\text { nieder- } \\
\text { geschlagen } \mathrm{Cu} \\
\mathrm{g}\end{array}$} & \multirow{2}{*}{$\begin{array}{c}\text { Dem Cu ent- } \\
\text { sprechender } \\
\text { Sauerstoff } \\
\text { g }\end{array}$} & \multirow{2}{*}{ 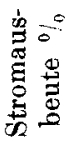 } & \multirow{2}{*}{ 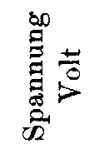 } \\
\hline & $\begin{array}{c}\text { Hypochlorit } \\
\mathrm{g}\end{array}$ & $\begin{array}{c}\text { Cblorat } \\
\mathrm{g}\end{array}$ & & & & \\
\hline $5-7$ & & 0.67 & 4.62 & 1.1 & 65.3 & $9.5-10$ \\
\hline 30 & 0.0135 & 0.6652 & 4.83 & 1.213 & 56.0 & 6.0 \\
\hline 52 & 0.0098 & 0.6410 & 4.82 & 1.212 & 53.7 & 5.5 \\
\hline
\end{tabular}

Hier nimmt ähnlich wie in neutralen Lösungen mit steigender Temperatur der Gehalt an Hypochlorit ab, und zwar verhältnismälsig schneller. Da in allen Fällen die kathodische Stromdichte dieselbe war, so könnte man einwenden, dals der Verlust an Hypochlorit einer vermehrten Reduktion bei erhöhter Temperatur zuzuschreiben sei. Diesen Einwand machen jedoch zwei Versuche OETTEL's hinfällig, bei denen eine Lösung von $20 \mathrm{~g} \mathrm{KCl}$ und $1 \mathrm{~g}$ $\mathrm{KOH}$ in $100 \mathrm{ccm}$ als Elektrolyt diente und deren Endergebnis folgendes war: 


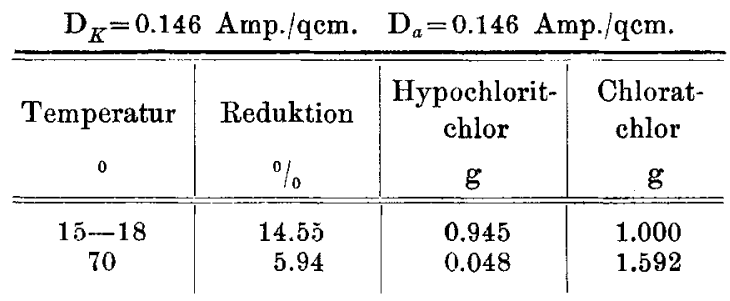

Alle diese Versuche weisen darauf hin, dafs thatsächlich die Verminderung des Hypochlorits im wesentlichen an der Anode erfolgt, wie es zu erwarten ist, wenn es daselbst in konzentrierterer Lösung auftritt. Denn nach Förster und JORRE ${ }^{1}$ erlordert eine konzentrierte Lösung von Hypochlorit bei $0^{0}$ viele Stunden zur Umwandlung in Chlorat, während eine solche Umwandlung bei $50^{\circ}$ in weniger als 5 Minuten sich fast vollständig vollzieht.

Dafs bei schwach alkalischen Lösungen die für neutrale Lösungen gültige Betrachtungsweise Platz behalten darf, die in ihnen herrschende Hydroxylkonzentration also für die anodischen Vorgänge nicht unmittelbar bestimmend sein kann, folgt auch aus der Thatsache, dafs die Stromausbeute in Chlorkaliumlösungen, die $1 / 4$ normal alkalisch sind, auch bei lange fortgesetzter Elektrolyse mit einer anodischen Stromdichte von 0.075 bis 0.08 Amp.qcm fast völlig konstant blieb, die anodische Sauerstoffentwickelung nur von 34 auf $37 \%$ der Stromarbeit anstieg, während mehr als die Hälfte des Chlorkaliums in Chlorat verwandelt wurde. Bei äquivalent zusammengesetzten Lösungen der Natriumverbindungen traten etwas andere Verhältnisse ein, da hier, wie auch OEтTEL hervorhob, das Chlorat in der Lösung bleibt und seine Anionen bei höherer Konzentration an den Entladungsvorgängen teilnehmen können.

Die Kurve, Fig. 13, welche die Ergebnisse von Versuch 27 wiedergiebt, zeigt bei $1.5 \mathrm{~g} \mathrm{NaOH}$ in $100 \mathrm{ccm}$ für die Chloratbildung ein Maximum. Bei diesem Gehalt an Alkali ist das Hypochlorit auf einen so geringen Wert angelangt, dafs die nutzbringende Stromarbeit so gut wie ausschliefslich in der Chloratbildung besteht. Da nun, wie OETTEL fand, auch die Sauerstoffentwickelung an der Anode mit weiter steigendem Alkaligehalt wächst, so ist klar, dafs von jenem Punkte ab die Chloratbildung wieder abnehmen mufs. 
Gerade die von diesem Punkte an bei der Elektrolyse auftretenden Verhältnisse waren es, die bei den obigen Darlegungen zur Annahme einer primären Chloratbildung in stärker alkalischen Lösungen drängten; sie stehen in einem gewissen Gegensatz zu den eben erörterten und bedürfen deshalb einer gesonderten Betrachtung.

\section{C. Über die Natur der in stärker alkalischen Chloridlösungen sich abspielenden anodischen Vorgänge.}

War es leicht, das Vorhandensein einer primären Chloratbildung an der Anode bei der Elektrolyse stärker alkalischer Chloridlösungen zu erkennen und liefs sich auch für bestimmte Versuchsbedingungen mit einiger Wahrscheinlichkeit die Grenze des Alkaligehaltes ungefähr angeben, oberhalb deren dieser Vorgang einsetzt, so ist es doch nach dem vorliegenden Versuchsmaterial noch nicht möglich, ein bestimmtes Urteil über die Natur dieses Vorganges auszusprechen.

Es bestehen vielmehr eine Anzahl von Möglichkeiten, von denen zur Zeit keiner der Vorzug zu geben ist. Die Erwägungen hierüber sollen jedoch nicht übergangen werden. Sie kennzeichnen die einer bestimmten Deutung entgegenstehenden Schwierigkeiten und können vielleicht für spätere Untersuchungen zur richtigen Fragestellung beitragen.

An die Spitze dieser Betrachtungen sei die Thatsache gestellt, dafs bei dem höchsten in Anwendung gekommenen Alkaligehalt sowohl bei den vorliegenden sowie bei den von OETTEL und WoHIwILL angestellten Versuchen die Hypochloritbildung nie ganz ausblieb. Auch in einer in Bezug auf freies Alkali normalen Chlornatriumlösung entsteht von Anfang an Hypochlorit und nimmt seiner Menge nach immer langsamer $\mathrm{zu}$, bis ein konstanter Wert erreicht ist.

Dies zeigen in Übereinstimmung mit den WoHLwILL'schen die folgenden Versuche. Bei ihnen wurde die durch Fig. 12 wiedergegebene Versuchsanordnung eingehalten. Die jedesmal in der Lösung befindlichen Hypochloritmengen waren so gering, dafs zwecks genauer Bestimmung stets die ganze Lösung zur Bestimmung benutzt, also der Versuch immer wieder von neuem angesetzt und nach verschiedenen Zeiten abgebrochen wurde. 
Versuch 35.

Die Stromstärke betrug 4 Amp. Temperatur $6-8^{\circ} \mathrm{C}$.

Die Lösung $(200 \mathrm{ccm})$ enthielt $20 \% \mathrm{NaCl}+4 \% \mathrm{NaOH}$. $\mathrm{D}_{K}=1.14 \mathrm{Amp} . / \mathrm{qcm} . \mathrm{D}_{a}=0.04 \mathrm{Amp} . / \mathrm{qcm}$.

Spannung 10 Volt.

\begin{tabular}{|c|c|c|c|c|c|}
\hline \multirow{2}{*}{ 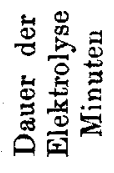 } & \multicolumn{2}{|c|}{$\begin{array}{c}\text { Aktiver Sauersfoff } \\
\text { als }\end{array}$} & \multirow{2}{*}{$\begin{array}{l}\text { Im Voltameter } \\
\text { nieder- } \\
\text { geschlagen } \mathrm{Cu} \\
\mathrm{g}\end{array}$} & \multirow{2}{*}{$\begin{array}{c}\text { Dem Cu ent- } \\
\text { sprechender } \\
\text { Sauerstoff } \\
g\end{array}$} & \multirow{2}{*}{$\begin{array}{c}\text { Strom- } \\
\text { ausbeute } \\
\%\end{array}$} \\
\hline & $\begin{array}{c}\text { Hypochlorit } \\
\mathrm{g}\end{array}$ & $\begin{array}{c}\text { Chlorat } \\
\mathrm{g}\end{array}$ & & & \\
\hline 5 & 0.00093 & 0.046 & 0.405 & 0.1022 & 46.3 \\
\hline 20 & 0.00315 & 0.179 & - & - & - \\
\hline 40 & 0.00265 & 0.345 & 3.035 & 0.7660 & 45.2 \\
\hline 60 & 0.00286 & 0.553 & 4.830 & 1.2190 & 45.6 \\
\hline
\end{tabular}

Versuch 36.

Temperatur $52^{\circ} \mathrm{C}$.

Die Lösung $(200 \mathrm{ccm})$ enthielt $20 \% \mathrm{NaCl}+4 \% \mathrm{NaOH}$.

$\mathrm{D}_{K}=1.14 \mathrm{Amp} . / \mathrm{qcm}$. $\mathrm{D}_{a}=0.04 \mathrm{Amp} / \mathrm{qcm}$.

\begin{tabular}{|c|c|c|c|c|c|}
\hline \multirow{3}{*}{ 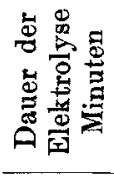 } & \multicolumn{2}{|c|}{$\begin{array}{c}\text { Aktiver Sauerstoff } \\
\text { als }\end{array}$} & \multirow{3}{*}{$\begin{array}{l}\text { Im Voltameter } \\
\text { nieder- } \\
\text { geschlagen } \mathrm{Cu} \\
\mathrm{g}\end{array}$} & \multirow{3}{*}{$\begin{array}{c}\text { Dem Cu ent- } \\
\text { sprechender } \\
\text { Sauerstoff } \\
\text { g }\end{array}$} & \multirow{3}{*}{$\begin{array}{c}\text { Strom- } \\
\text { ausbeute } \\
\%\end{array}$} \\
\hline & Hypochlorit & Chlorat & & & \\
\hline & $\mathrm{g}$ & $\mathrm{g}$ & & & \\
\hline 2 & 0.0015 & 0.0095 & 0.115 & 0.039 & 28.3 \\
\hline 5 & 0.0058 & 0.0258 & 0.450 & 0.113 & 27.8 \\
\hline 40 & 0.0105 & 0.2269 & 3.110 & 0.785 & 30.2 \\
\hline 60 & 0.0135 & 0.3185 & 4.800 & 1.219 & 27.2 \\
\hline 90 & 0.0139 & 0.4213 & 7.030 & 1.774 & 24.5 \\
\hline
\end{tabular}

Aus diesem Verhalten des Hypochlorits geht hervor, dals es auch in stark alkalischen Lösungen weiter in Chlorat verwandelt wird, dals also auch hier letztere Verbindung aus Hypochlorit entstehen kann, was auch aus den Versuchen 24-26 hervorgeht.

Es fragt sich aber, ob alles Chlorat in stärker alkalischer Lösung über Hypochlorit hinweg entsteht, oder ob dessen Umwandlung hier nur ein Nebenvorgang ist und ob die Hauptmenge des Chlorats auf einem anderen Wege unmittelbar aus Chlorionen entsteht.

Es soll zunächst angenommen werden, dals alles Chlorat über Hypochlorit hinweg sich bildet. Worin würde dann der Unterschied bestehen zwischen der Chloratbildung aus Hypochlorit in stärker alkalischen Lösungen gegenüber derjenigen in neutralen und schwächer alkalischen? 
Unzweifelhaft entsteht auch in ersteren sekundär Hypochlorit, wenn das Anodenpotential höher liegt als das Entladungspotential der Chlorionen, so dals diese am Entladungsvorgang sich beteiligen. Seine Konzentration in unmittelbarer Nähe der Anode wird in stark alkalischen Lösungen eine besonders hohe sein. Doch ist zu bemerken, dafs sie sich schliefslich einem Grenzwert nähern wird; denn je höher die Alkalität steigt, um so weniger Chlor wird entladen werden, um so weniger Hypochlorit kann entstehen, das dann freilich durch den Alkaliüberschufs besonders nahe an der Anode gehalten wird. Diese beiden Einflüsse wirken gegen einander und dürften schliefslich zu einer ungefähren Konstanz der Hypochloritkonzentration an der Anode führen.

Diese konzentrierte Lösung wird nun, ähnlich wie es die alkalische reine Hypochloritlösung thut, auf zweierlei Weise in Chlorat umgewandelt. Die sekundäre Chloratbildung wird mit zunehmendem Alkaligehalt immer mehr zurücktreten, wie ein Vergleich der Versuche 4 und 24 lehrt, und es wird für die primäre Oxydation eine immer konzentriertere Hypochloritlösung übrig bleiben. Da diese an der Anode als sehr konzentriert gedacht werden kann, so darf eine auch bei gewöhnlicher Temperatur sehr schnell und weitgehend verlaufende Oxydation durch anodischen Sauerstoff als nichts Unwahrscheinliches gelten.

Nach dieser Auffassung würde also die Chloratbildung in stark alkalischen Chloridlösungen von derjenigen in schwächer alkalischen, neutralen und schwach sauren, nur dem Grade, nicht dem Wesen nach verschieden sein, indem hier die sekundäre, dort die primäre Oxydation des Hypochlorits überwiegt, ohne sich gegenseitig, wenigstens in der Kälte, ganz auszuschliefsen.

$\mathrm{Zu}$ betonen ist, dafs, wenn überhaupt sekundär Hypochlorit entsteht, auch hier die Konzentrationsverhältnisse, die für die Entladungserscheinungen mafsgebend sind, an der Anode andere sein werden wie in der übrigen Lösung. Denn durch die Hypochloritbildung verarmt die Lösung an der Anode an Hydroxyl und erhält ihren Verlust an Chlorionen teilweise wieder ersetzt; es wird also das für die Entladung in Betracht kommende Konzentrationsverhältnis von $\mathrm{OH}: \overline{\mathrm{Cl}}$ mehr zu Gunsten der letzteren sich gestalten, als es die Zusammensetzung der Lösung anzeigt. An der anodischen Sauerstoffentwickelung wird wieder das Hypochlorit reichlich teilnehmen und es ist eine schwer zu beantwortende Frage, ob, wenn meine Annahme zutrifft, nicht auch in stärker alka- 
lischen Lösungen an der Anode wesentlich Hypochlorit und kaum Hydroxyl verweilt und das hier herrschende Konzentrationsverhältnis der $\overline{\mathrm{Cl}}$ - und $\overline{\mathrm{ClO}}$-Ionen für die Sauerstoffentwickelung in erster Linie malsgebend wäre. In jedem Falle würde mit steigendem Alkaligehalt der Lösung die Sauerstoffentwickelung zunehmen.

Die primäre Oxydation des Hypochlorits geht bei höherer Temperatur sehr zurück und an ihre Stelle tritt die in der Wärme stark beschleunigte sekundäre Hypochloritbildung. Da aber hierbei das zunächst entstandene Hypochlorit sich gewissermalsen unter sich selbst oxydiert und keine direkte Zufuhr von aktivem Sauerstoff erfährt, so muls die gesamte Stromausbeute an Sauerstoff abnehmen, während die Sauerstoffentwickelung entsprechend zunimmt.

Denkt man sich, dafs in einer in Bezug auf $\mathrm{NaOH}$ normalen Chlornatriumlösung bei $0^{\circ} \mathrm{C}$. die Chloratbildung ausschliefslich durch primäre Oxydation von Hypochlorit im Sinne der Gleichung a), bei $75^{\circ}$ aber lediglich sekundär im Sinne der Gleichung b) entsteht
a) $3 \mathrm{NaClO}+3 \mathrm{O}_{2}=3 \mathrm{NaClO}_{3}$
b) $3 \mathrm{NaClO}=\mathrm{NaClO}_{3}+2 \mathrm{NaCl}$,

so mufs die Stromausbeute im letzten $1 / 3$ derjenigen im ersten Falle sein. Thatsächlich wurden im Versuch 28 bei $6^{\circ}$ eine Stromausbeute von $45.6 \%$ und bei $75^{\circ}$ eine solche von nur $17 \%$ beobachtet, was angesichts des Umstandes, dal's die oben angenommene Ausschliefslichkeit bei keinem der beiden Vorgänge genau zutrifft, als Bestätigung der Theorie gelten kann.

Die gemachte Annahme, dals auch in stärker alkalischen Lösungen alles elektrolytisch entstehende Chlorat über das Hypochlorit hinweg entstanden ist, deckt sich also in ihren Folgerungen mit den Thatsachen. Doch lälst sie dieser Umstand noch nicht als gesichert gelten; denn einerseits stützt sich die obige Beweisführung auf die bypothetische Zugrundelegung der Konzentrationsverhältnisse an der Anode und andererseits lassen sich die beobachteten Erscheinungen noch auf andere Weise deuten.

So genügt z. B. ebenfalls den Thatsachen die Annahme, dafs bei hohem Anodenpotential mit steigender Alkalität des Elektrolyten und damit vermehrter Sauerstoffentwickelung ein primärer elektrochemischer Vorgang möglich wird, durch welchen unmittelbar Chlorionen zu Chlorationen oxydiert werden. Man mufs nur fordern, dafs auch dieser Vorgang die Eigentümlichkeit besitzt, durch hohes Anodenpotential begünstigt und durch Temperatursteigerung beein- 
trächtigt zu werden. Das in der Lösung auftretende Hypochlorit würde dann nur von seiten derjenigen Cl-Ionen gebildet werden, welche diesem Oxydationsvorgang nicht anheimfielen, und würde seinerseits teils durch sekundäre, teils durch primäre Oxydation an der Chloratbildung, die sich dann aus drei verschiedenen Vorgängen zusammensetzte, teilnehmen.

Eine unmittelbare Entstehung von Chlorat einer bei der Elektrolyse reichlich Sauerstoff entwickelnden Chloridlösung denkt sich HABER im Sinne der Gleichung

$$
\overline{\mathrm{Cl}}+5 \overline{\mathrm{OH}}+6(+)=\mathrm{HClO}_{3}+2 \mathrm{H}_{2} \mathrm{O}
$$

als auf einer Aneinanderlagerung von Chlor- und Hydroxylionen im Augenblick der Entladung beruhend. Dals die von WoHLwILl gegen die Heranziehung dieser Theorie zur Deutung der elektrolytischen Chloratbildung in alkalischer Lösung erhobenen Bedenken nicht ausreichend begründet sind, ist in der theoretischen Abhandlung bereits auseinandergesetzt. In der That spricht auch keine der oben angeführten Beobachtungen eindeutig gegen die Möglichkeit, in stärker alkalischen Chloridlösungen einen anodischen Vorgang im Sinne der HABER'schen Auffassung anzunehmen.

Aber diese ist nicht die einzige Auffassung, welche man sich über die Art des Vorganges einer primären Oxydation von $\overline{\mathrm{Cl}}$-Ionen zu $\overline{\mathrm{ClO}}_{3}$-Ionen bilden kann. Die Beobachtungen von FöRs'TER und JoRRE ${ }^{1}$ haben gelehrt, dafs ebenso wie $\overline{\mathrm{Cl}} \mathrm{O}-$ Ionen auch - freilich sehwerer - $\overline{\mathrm{Cl}}$-Ionen durch unterchlorige Säure za $\overline{\mathrm{ClO}} \mathrm{O}_{3}$-Ionen oxydiert werden können.

Wir sahen, dals Hypochlorit primär der anodischen Oxydation unterliegen kann; sollte denn für Cl-Ionen nicht eine ähnliche Möglichkeit bestehen und zwar besonders dann, wenn das Anodenpotential ein hohes ist?

Eine solche Oxydation würde sich nicht auf sich entladende, sondern auf in der Lösung befindliche Chlorionen erstrecken und eine solche Annahme würde auch der Hydroxylionen im Entladungsmoment entbehren und nur den an der Anode auftretenden Sauerstoff als wirksam betrachten.

Hat, wie man weils, der kathodisch auftretende Wasserstoff besondere reduzierende Eigenschaften, so hindert nichts, auch dem

1 a. a. $\mathrm{O}$. 
anodischen Sauerstoff besondere Fähigkeiten zuzuschreiben, Oxydationsprozesse auszuführen, die wir auch auf rein chemischem Wege ausüben können.

An der Anode wären dann folgende primären Oxydationsvorgänge möglich:

$$
\begin{aligned}
\mathrm{ClO}+2 \mathrm{O} & =\overline{\mathrm{ClO}}_{3} \\
\overline{\mathrm{Cl}}+3 \mathrm{O} & =\overline{\mathrm{ClO}}_{3} \\
\mathrm{ClO}_{3}+\mathrm{O} & =\overline{\mathrm{ClO}}_{4} .
\end{aligned}
$$

Der letztere Vorgang kann zwar auf rein chemischem Wege in wässeriger Lösung bisher noch nicht durchgeführt werden. ${ }^{1}$

Alle drei Vorgänge wären durch Temperatursteigerung beeinträchtigt und wenigstens die beiden letzten durch hohes Potential begünstigt.

Die Annahme einer Oxydation von $\overline{\mathrm{Cl}}-$ Ionen ist also nicht von vornherein abzuweisen. Mit ibrer Hilfe kann man die Erscheinungen bei der Elektrolyse stärker alkalischer Alkalichloridlösugen folgendermalsen deuten:

An der Anode werden anfangs $\overline{\mathrm{Cl}}-$ und $\overline{\mathrm{OH}}-$ Ionen in dem Mafse neben einander entladen, wie es ihrem Konzentrationsverhältnis in der Lösung entspricht. Je mehr Cl-Ionen entladen werden, umsomehr Hypochlorit entsteht und erleidet seinerseits die ihm eigentümlichen Umwandlungen. Durch die $\overline{\mathrm{OH}}$-Entladung, für welche später diejenige der ClO-Ionen mehr oder weniger eintreten kann, wird Sauerstoff an der Anode entwickelt und bethätigt sich umso mehr oxydierend an in der Lösung befindlichen C̈-Ionen, in je gröfserer Menge er entsteht und je mehr von diesen, in Zusammenhange hiermit, unentladen in der Lösung bleiben. Macht man, wie es geschah, das Zustandekommen dieses Vorganges abhängig von einem hohen Anodenpotential, welches über dem Entladungspunkte der Chlorionen liegt, so ist es einleuchtend, dafs er merklich erst in stärker alkalischen Lösungen in Erscheinung treten kann, da hier eben trotz hohen Potentials an der Anode viel Cl-Ionen in Lösung bleiben und mit freiwerdendem Sauerstoff zusammentreffen. Durch diesen Vorgang aber verarmt auch die Lösung an der Anode an Cl-Ionen;

1 Dagegen hat Falnuey (Jahresber. Chem. 1874, 210) die Oxydation der unterchlorigen Säure und ihrer Salze zu Überchlorsäure und deren Salzen dureh ozonisierte Luft beobachtet. 
wird er also bei höherer Temperatur beeinträchtigt, so bleiben mehr $\overline{\mathrm{C}}$-Ionen zur Entladung übrig. So könnten die Beobachtungen in heifsen, stärker alkalischen Lösungen ihre Deutung finden.

Man sieht, dafs auch die Vorstellung von einer unmittelbaren anodischen Oxydation von Chlorionen zur Deutung aller Erscheinungen nicht ohne manche willkürliche Annahme, die der experimentellen Prüfung schwer zugänglich ist, anwendbar ist. Sie erscheint also der ersten Annahme, von der stets durch Vermittelung des Hypochlorits stattfindenden Chloratbildung nicht überlegen. Es läfst sich jedoch zu ihren Gunsten anführen, dafs die von Haber und GrinBERG studierte Chlorsäurebildung bei der Elektrolyse verdünnter Salzsäurelösungen sich bei der Annahme einer anodischen Oxydation von C̄-Ionen unter gleichen Gesichtspunkten behandeln läfst, wie die elektrolytische Chloratbildung in stark alkalischen Lösungen. In ersterem Falle ist die Vermittelung der neben Salzsäure in nennenswertem Umfange nicht existenzfähigen unterchlorigen Säure ausgeschlossen. Weiter aber hat dieser Vorgang der Chlorsäurebildung, den man abweichend von HABER auch im Sinne der Gleichung

$$
\mathrm{Cl}+3 \mathrm{O}=\mathrm{ClO}_{3}
$$

sich abspielend denken kann, mit dem Teile der Chloratbildung in alkalischen Lösungen, den wir auf einen primären Vorgang zurückführten, so grofse Ähnlichkeit, dafs man kaum umhin kann, zu versuchen, beide unter die gleichen Gesichtspunkte unterzuordnen.

Diese Ähnlichkeit besteht darin, dafs auch die Chlorsäurebildung aus verdünnter Salzsäure durch hohes Anodenpotential begünstigt und durch Temperatursteigerung beeinträchtigt wird, doch auch so, dafs hohe Stromdichte den störenden Einflufs der Temperaturerhöhung bis zu einem gewissen Grade auszugleichen vermag.

Hierzu kommt, dafs nach HaBer und Grinberg Platinierung der Anode die Bildung von Chlorsäure vermindert. Dafs auch auf die Chloratbildung die Platinierung ganz ähnlich wirkt, zumal in stärker alkalischen Lösungen, soll noch durch Versuche näher erläutert werden.

\section{Einflufs der Platinierung auf die elektrolytische Chloratbildung aus Alkalichloridlösungen.}

Auf gewöhnlichem Wege bewirkte graue Platinierung hat einen nur geringen Einflufs auf den Verlauf der Elektrolyse von Chlor- 
alkalilösungen; derselbe wird aber sehr bedeutend, wenn die Platinierung aus schwach bleihaltiger Lösung nach LuMmer und KuRLBAUM geschieht, zumal dann, wenn durch länger fortgesetzte Platinierung die Schicht des Platinschwammes eine starke wird.

Im Verlauf einer Elektrolyse vermindert sich die Wirksamkeit einer Platinierung, wie in der folgenden Übersicht die allmähliche Abnahme der Sauerstoffentwickelung in alkalischer Lösung deutlich zeigt, nicht unerheblich. Es wurde deshalb die Anode nach jedem Gebrauch eine bestimmte Zeit nachplatiniert. Infolge dieses Umstandes sind die einzelnen Versuche nur annähernd unter sich vergleichbar.

Die folgenden Versuche sind in dem zu vielen der früheren benutzten Becher mit je $480 \mathrm{ccm}$ Lösung ( $20 \mathrm{~g}$ Chlornatrium in $100 \mathrm{ccm}$ ) ausgeführt, und zwar mit einer auf die glatte Anodenoberfläche bezogenen Stromdichte von $0.04 \mathrm{Amp} . / \mathrm{qcm}$, wie sie bei Versuch 27 und 28 benutzt wurde. Da aber hier die Anode kleiner war wie bei diesen Versuchen, so wurde mit der Stromstärke von $2 \mathrm{Amp}$. gearbeitet, und um gleiche Strommenge wie dort anzuwenden, der Versuch 2 Stunden fortgesetzt. Die Temperatur betrug $3-5^{0} \mathrm{C}$. Die Ergebnisse sind in der folgenden Übersicht zusammengestellt. Es wurden die Versuche in stärker alkalischen $(4 \mathrm{~g} \mathrm{NaOH}$ in $100 \mathrm{ccm}$ ) und zum Vergleich auch in schwächer alkalischen $(1 \mathrm{~g} \mathrm{NaOH}$ in $100 \mathrm{ccm}$ ) und in neutralen Lösungen durchgeführt.

\section{Übersicht 2.}

$R=$ Reduktion. $S=$ Sauerstoffentwickelung. $A=$ Stromausbeute in Prozenten.

Die Lösung enthielt $20 \mathrm{~g} \mathrm{NaCl}$ in $100 \mathrm{ccm}+4 \mathrm{~g} \mathrm{NaOH}$.

\begin{tabular}{|c|c|c|c|c|c|c|c|c|c|c|c|c|}
\hline \multirow{2}{*}{$\begin{array}{r}\text { Zeit } \\
\text { Stdn. } \\
\end{array}$} & \multicolumn{3}{|c|}{ Glatte Anode } & \multicolumn{3}{|c|}{$\begin{array}{c}\text { Anode grau } \\
\text { platiniert }\end{array}$} & \multicolumn{3}{|c|}{$\begin{array}{l}\text { Anode } 2 \text { Min. } \\
\text { nach L. und K. } \\
\text { platiniert }\end{array}$} & \multicolumn{3}{|c|}{$\begin{array}{l}\text { Anode } 1 / 4 \text { Stunde } \\
\text { nach L. und K. } \\
\text { platiniert }\end{array}$} \\
\hline & $R$ & $S$ & $A$ & $R$ & $S$ & $A$ & $R$ & $S$ & $A$ & $R$ & $S$ & $A$ \\
\hline $\begin{array}{c}1 / 2 \\
1 \\
11 / 2 \\
2\end{array}$ & $\begin{array}{l}0.0 \\
0.0 \\
0.0 \\
0.0\end{array}$ & $\begin{array}{l}55.4 \\
55.4 \\
55.6 \\
57.5\end{array}$ & $\begin{array}{l}44.6 \\
44.6 \\
44.4 \\
42.5\end{array}$ & $\begin{array}{l}0.0 \\
0.0 \\
0.0 \\
0.0\end{array}$ & $\begin{array}{l}58.7 \\
60.0 \\
60.9 \\
60.3\end{array}$ & $\begin{array}{l}41.3 \\
40.0 \\
39.1 \\
39.7\end{array}$ & $\begin{array}{l}0.0 \\
0.4 \\
1.2 \\
1.3\end{array}$ & $\begin{array}{l}88.5 \\
85.0 \\
81.5 \\
83.9\end{array}$ & $\begin{array}{l}11.5 \\
14.6 \\
17.3 \\
14.8\end{array}$ & $\begin{array}{l}0.0 \\
0.0 \\
0.2 \\
0.7\end{array}$ & $\begin{array}{l}95.6 \\
95.6 \\
94.1 \\
94.5\end{array}$ & $\begin{array}{l}4.4 \\
4.4 \\
5.7 \\
4.8\end{array}$ \\
\hline \multicolumn{2}{|c|}{$\begin{array}{l}\text { Hypochlorit- } \\
\text { sauerstoff }\end{array}$} & \multicolumn{2}{|c|}{ Spur } & \multicolumn{3}{|c|}{ Spur } & \multicolumn{3}{|c|}{$0.0622 \mathrm{~g}$} & \multicolumn{2}{|c|}{$0.0276 \mathrm{~g}$} & \\
\hline \multicolumn{2}{|c|}{$\begin{array}{l}\text { Strom- } \\
\text { ausbeute }\end{array}$} & \multicolumn{2}{|c|}{$43.5 \%$} & \multicolumn{3}{|c|}{$39.2 \%$} & \multicolumn{3}{|c|}{$11.8 \%$} & \multicolumn{3}{|c|}{$3.1 \%$} \\
\hline
\end{tabular}


Die Lösung enthielt $20 \mathrm{~g} \mathrm{NaCl}$ in $100 \mathrm{ccm}+1 \mathrm{~g} \mathrm{NaOH}$.

\begin{tabular}{|c|c|c|c|c|c|c|c|c|c|}
\hline Zeit & \multicolumn{3}{|c|}{ Glatte Anode } & \multicolumn{3}{|c|}{$\begin{array}{l}\text { Anode } 2 \text { Min. nach } \\
\text { L. u. K. platiniert }\end{array}$} & \multicolumn{3}{|c|}{$\begin{array}{l}\text { Anode } 1 / 4 \text { Stde. nach } \\
\text { L. u. K. platiniert }\end{array}$} \\
\hline Stunden & $R$ & $S$ & $A$ & $R$ & $S$ & $A$ & $R$ & $S$ & $A$ \\
\hline $\begin{array}{c}1 / 2 \\
1 \\
11 / 2 \\
2\end{array}$ & $\begin{array}{l}4.3 \\
6.9 \\
- \\
9.8\end{array}$ & $\begin{array}{l}23.4 \\
26.4 \\
\overline{30.1}\end{array}$ & $\begin{array}{c}72.4 \\
66.6 \\
- \\
60.1\end{array}$ & $\begin{array}{l}2.7 \\
4.7 \\
6.0 \\
6.5\end{array}$ & $\begin{array}{l}44.8 \\
39.0 \\
38.7 \\
37.9\end{array}$ & $\begin{array}{l}52.5 \\
56.3 \\
55.3 \\
55.6\end{array}$ & $\begin{array}{l}0.6 \\
2.5 \\
4.5 \\
7.2\end{array}$ & $\begin{array}{l}81.4 \\
71.3 \\
63.5 \\
60.2\end{array}$ & $\begin{array}{l}18.0 \\
26.2 \\
32.0 \\
32.6\end{array}$ \\
\hline $\begin{array}{l}\text { Hypochlorit- } \\
\text { sauerstoff }\end{array}$ & \multicolumn{3}{|c|}{$0.2243 \mathrm{~g}$} & \multicolumn{3}{|c|}{$0.1336 \mathrm{~g}$} & \multicolumn{3}{|c|}{$0.1459 \mathrm{~g}$} \\
\hline $\begin{array}{l}\text { Chlorat- } \\
\text { sauerstoff }\end{array}$ & \multicolumn{3}{|c|}{0.5898,} & \multicolumn{3}{|c|}{0.5077,} & \multicolumn{3}{|c|}{0.1383} \\
\hline $\begin{array}{l}\text { Strom- } \\
\text { ausbeute }\end{array}$ & \multicolumn{3}{|c|}{$66.7 \%$} & \multicolumn{3}{|c|}{$51.9 \%$} & \multicolumn{3}{|c|}{$23.2 \%$} \\
\hline
\end{tabular}

Die Lösung enthielt $20 \mathrm{~g} \mathrm{NaCl}$ in $100 \mathrm{ccm}$ und war neutral.

\begin{tabular}{|c|c|c|c|c|c|c|c|c|c|}
\hline Zeit & \multicolumn{3}{|c|}{ Glatte Anode } & \multicolumn{3}{|c|}{$\begin{array}{l}\text { Anode } 2 \text { Min. nach } \\
\text { L. u. K. platiniert }\end{array}$} & \multicolumn{3}{|c|}{$\begin{array}{l}\text { Anode } 1 / 4 \text { Stde. nach } \\
\text { I. u. K. platiniert }\end{array}$} \\
\hline Stunden & $R$ & $S$ & $A$ & $R$ & $S$ & $A$ & $R$ & $S$ & $A$ \\
\hline $\begin{array}{c}1 / 2 \\
1 \\
11 / 2 \\
2\end{array}$ & $\begin{array}{l}12.0 \\
21.1 \\
29.2 \\
35.7\end{array}$ & $\begin{array}{l}5.1 \\
6.1 \\
6.4 \\
7.4\end{array}$ & $\begin{array}{l}82.9 \\
72.8 \\
64.4 \\
56.9\end{array}$ & $\begin{array}{l}13.2 \\
20.5 \\
25.5 \\
30.1\end{array}$ & $\begin{array}{l}17.1 \\
26.7 \\
30.0 \\
26.6\end{array}$ & $\begin{array}{l}69.7 \\
52.8 \\
44.5 \\
43.4\end{array}$ & $\begin{array}{l}10.7 \\
17.9 \\
23.3 \\
28.3\end{array}$ & $\begin{array}{l}16.9 \\
29.8 \\
39.1 \\
39.2\end{array}$ & $\begin{array}{l}72.4 \\
52.3 \\
37.6 \\
32.5\end{array}$ \\
\hline $\begin{array}{l}\text { Hypochlorit- } \\
\text { sauerstoff } \\
\text { Chlorat- } \\
\text { sauerstoff }\end{array}$ & \multicolumn{3}{|c|}{$0.8102 \mathrm{~g}$} & \multicolumn{3}{|c|}{$0.6048 \mathrm{~g}$} & \multicolumn{3}{|c|}{$0.5856 \mathrm{~g}$} \\
\hline $\begin{array}{c}\text { Strom- } \\
\text { ausbeute }\end{array}$ & \multicolumn{3}{|c|}{$74.6 \%$} & \multicolumn{3}{|c|}{$55.4 \%$} & \multicolumn{3}{|c|}{$53.8 \%$} \\
\hline
\end{tabular}

Die Platinierung vergröfsert die Oberfläche der Anode aufserordentlich, sodafs die Stromdichte stark vermindert wird. Man mufs jedoch berücksichtigen, dal's eine platinierte Elektrode Spitzen und Vertiefungen aufweist, sodafs die Stromdichte keinesfalls gleichmälsig über dieselbe verteilt sein kann. ${ }^{1}$

Besonders erschwerend für eine eingehende Deutung wirkt der Umstand, dafs die schwammige Beschaffenheit der platinierten Ober-

: In diesem Sinne ist die Thatsache sehr bemerkenswert, dal's selbst eine sehr vollkommene Platinierung der Kathode auch in neutraler Chloralkalilösung nicht die geringste Veränderung des gefundenen Reduktionswertes gegenüber glatter Kathode herbeiführt. 
fläche den Ausgleich der anodisch veränderten Lösung mit dem übrigen Elektrolyten beeinträchtigt.

Ganz allgemein zeigen die Versuche, daß mit der Platinierung ein Rückgang der Stromausbeute verbunden ist. Dieser ist verhältnismälsig am stärksten bei höherem Gehalt an Alkali. Hier tritt aufserdem bei Verstärkung der Platinierung das Hypochlorit dem Chlorat gegenüber immer mehr in den Vordergrund, so wie es bei WoHLwrLL's ${ }^{1}$ Versuchen der Fall war, wenn das Anodenpotential sehr niedrige Werte annahm. Die Platinierung wirkt also hier ganz in demselben Sinne, wie eine Verminderung des Anodenpotentials.

Bei schwächer alkalischen Lösungen ist der Einflufs der Platinierung geringer. Ähnlich wie bei OETTEL's ${ }^{1}$ Versuchen wird auch hier bei einer Verminderung der Stromdichte resp. des Anodenpotentials anfangs die Hypochloritmenge gegenüber der des Chlorats vermindert und erst bei sehr vollkommener Platinierung tritt die letztere erheblich zurück.

Am wenigsten verändernd wirkt die Platinierung auf die Elektrolyse neutraler Chloridlösungen, wo wiederum, wie auch sonst bei verminderter Stromdichte, die anodische Sauerstoffentwickelung stark ansteigt und damit die Stromausbeute sinkt. Eine unter diesen Umständen an glatten Anoden beobachtete Verschiebung der Mengenverhältnisse zwischen Hypochlorit und Chlorat zu Gunsten des ersteren tritt hier nicht erheblich zu Tage. Diese Thatsache ist möglicherweise in der Verschiedenheit der in beiden Fällen an der Anode herrschenden Konzentrationsverhältnisse begründet, die vielleicht auch die sehr merkwürdige Thatsache erklärt, dafs unter den bei den obigen Versuchen eingehaltenen Bedingungen bei starker Platinierung sich reichlich Ozon bildete, wenn man neutrale Lösungen elektrolysierte, während dies bei alkalischen Lösungen nicht der Fall war; das ist gerade die umgekehrte Erscheinung wie man sie an glatten Anoden beobachtet.

Es sei schiefslich noch erwähnt, dafs an stark platinierten Elektroden sich auch das Perchlorat nur in sehr geringer Menge bildet. Bei der Elektrolyse von Natriumchloratlösungen (50 $\mathrm{g} \mathrm{NaClO}_{3}$ in $100 \mathrm{ccm}$ ) betrug an glatter Anode die Ausbeute an Perchlorat $95 \%$, an stark platinierter aber nur $19 \%$.

$\mathrm{Ob}$ in allen diesen Fällen nur die Verminderung des Anodenpotentials für die Erscheinungen mafsgebend ist, oder ob die Plati-

a. a. 0 . 
nierung einen besonderen störenden Einflufs auf die an glatten Anoden sich abspielenden Vorgänge ausübt, mufs dahingestellt bleiben.

\section{Schlufs.}

Bei Erörterung der vorstehend mitgeteilten Beobachtungen sind die Erscheinungen wiederholt mit den von OETTEL wie von HaBer und Grinberg gefundenen Thatsachen verglichen worden. Die Ergebnisse WoHLwILL's aber konnten nur zum Teil herangezogen werden, da die von ihm gewählten Versuchsbedingungen von den meinigen $\mathrm{zu}$ verschieden waren.

Es erübrigt daher zum Schlusse nur noch, auch diese mit den obigen in Beziehung zu setzen.

WoHLwiLl hat, wie mehrfach hervorgehoben, in erster Linie dargethan, dafs auch in schwach alkalischen Chlornatriumlösungen erst dann eine merkliche Elektrolyse eintritt, wenn die Spannung an den Elektroden etwa 2.0 Volt beträgt. Bei dieser tritt unter den erwähnten Bedingungen die Entladung von Cl-Ionen ein, welche dann ihrerseits zunächst Hypochlorit bilden. Damit sind die im ersten Teil dieser Arbeit erörterten sekundären Vorgänge eingeleitet.

Aber auch unterhalb 2.0 Volt beobachtete WoHLwILL bei einer normal alkalischen Chloridlösung $(20 \mathrm{~g} \mathrm{NaCl}$ in $100 \mathrm{ccm}$ ) die Bildung von Chlorsauerstoffsalzen, und zwar sogar unterhalb der für die Entladung von Hydroxyl notwendigen Spannung von 1.68 Volt.

Diese Thatsache führt er zurück auf eine Oxydation der in der Lösung vorhandenen Cl-Ionen durch die O-Ionen, deren Entladungspunkt nach Nernst und Glaser ${ }^{1}$ bei 1.08 Volt liegt.

In der That lassen auch diese Beobachtungen keine andere Deutung zu, und man hat hier eine primäre Hypochloritbildung vor sich. Diese hat jedoch stets nur einen sehr geringen Umfang und dürfte ganz zurücktreten, sobald bei Spannungen über 2 Volt die Entladung von $\overline{\mathrm{Cl}}$-Ionen Platz greift. Praktisch wird daher in der That nur eine sekundäre Entstehung von Hypochlorit in Betracht kommen.

Weiter stellte WoHLwiL fest, dals eine schwach alkalische Chloridlösung, welche kleine Mengen von Hypochlorit enthält, ober-

${ }^{1}$ Ber. deutsch. chem. Ges. 30. 
halb des Entladungspunktes der Hydroxylionen einen viel lebhafteren Stromdurchgang aufwies, als ohne einen solchen Zusatz.

Einen für die Entladung von ClO-Ionen charakteristischen Knickpunkt der Zersetzungskurve für besagte Lösung konnte er nicht auffinden, und er folgert daraus, dals die ClO-Ionen, ehe sie entladen werden, der anodischen Oxydation unterliegen, ohne selbst an der Entladung teilzunehmen.

Diese primäre Oxydation der Anionen des Hypochlorits habe ich oben wiederholt nachgewiesen und ihre Bedeutung erörtert. $\mathrm{Ob}$ sie, wie WoHLwILl annimmt, im Sinne der Gleichung

$$
2 \overline{\mathrm{ClO}}+\overline{\mathrm{OH}}(++)=\mathrm{HClO}_{3}+\overline{\mathrm{Cl}} \text {, }
$$

oder, wie oben angeführt, nach der Gleichung

$$
\mathrm{ClO}+2 \mathrm{O}=\mathrm{ClO}_{3}
$$

verläuft, ist schwer mit Sicherheit zu entscheiden. Die Thatsache, dafs sie auch in neutraler Hypochloritlösung auftritt, spricht mehr zu Gunsten der letzteren Auffassung.

Aufser durch diesen Vorgang ist aber das Hypochlorit noch durch eine unmittelbare Entladung seiner Anionen an der Anode bei der Elektrolyse beteiligt. Das wurde oben eingehend erwiesen. Wenn WoHLwILI dies nicht bemerken konnte, so zeigt das nur, dafs bei sehr niedriger Stromdichte, wie er sie anwandte, ClO-Ionen leichter primär oxydiert als entladen werden. Dals aber ihr Entladungspunkt unter demjenigen des Chlors liegen mufste, wurde oben bewiesen.

Der primären Oxydation von ClO-Ionen im Sinne seiner oben angeführten Gleichung schreibt WoncwiLr die Chloratbildung in alkalischen Lösungen zu. Die Begünstigung derselben durch steigendes Anodenpotential führt er auf gesteigerte Chlorentladung und dadurch vermehrte Hypochloritbildung an der Anode zurück. Diese Auffassung hat eine gewisse Ähnlichkeit mit der oben erörterten Möglichkeit, die gesteigerte Chloratbildung durch die in stärker alkalischen Lösungen besonders hohe Konzentration des Hypochlorits dicht an der Anode zu erklären. Dafs sie aber keines. wegs zwingend ist, wurde oben klargelegt.

Es liels sich weder die HaBER'sche Vorstellung von einer unmittelbaren Vereinigung von Chlor und Hydroxyl im Momente der Entladung, noch die Annahme von der Hand weisen, dals ein der primären Hypochloritbildung ähnlicher, an hohes Anodenpotential 
gebundener Vorgang statthat, bei welchem anodischer Sauerstoff die in der Lösung vorhandenen Cl-Ionen zu Chlorat oxydiert.

Ob der eine oder der andere der letzterwähnten Vorgänge neben der obnedies schon vorhandenen, durch die Perchloratbildung noch erhöhten Mannigfaltigkeit der anodischen Erscheinungen bei der Alkalichloridelektrolyse wirklich in Betracht zu ziehen ist, muls der Entscheidung späterer Experimentaluntersuchungen vorbehalten bleiben.

Mir scheint es jedoch möglich auf Grund des vorliegenden Versuchsmaterials, die Entstebung der Chlorsäure bei der Elektrolyse sowohl verdünnter Salzsäure, als auch saurer, neutraler und alkalischer Alkalichloridlösungen durch folgende vier Gleichungen einheitlich und erschöpfend zu deuten:

$$
\begin{aligned}
& \text { 1. } \overline{\mathrm{Cl}}+3 \mathrm{HClO}=\overline{\mathrm{ClO}}_{3}+3 \stackrel{+}{\mathrm{H}}+3 \overline{\mathrm{Cl}}, \\
& \text { 2. } \overline{\mathrm{ClO}}+2 \mathrm{HClO}=\overline{\mathrm{ClO}}{ }_{3}+2 \stackrel{+}{\mathrm{H}}+2 \overline{\mathrm{Cl}}, \\
& \text { 3. } \overline{\mathrm{Cl}}+3 \mathrm{O}=\overline{\mathrm{ClO}_{3},} \\
& \text { 4. } \overline{\mathrm{ClO}}+2 \mathrm{O}=\overline{\mathrm{ClO}_{3}} .
\end{aligned}
$$

Danach ist die Chlorsäure da, wo $\overline{\mathrm{Cl}} \mathrm{O}$-Ionen nicht existensfähig sind, also in verdünnter Salzsäure nach Gleichung 3 , in allen anderen Fällen nach allen vier Gleichungen entstanden zu denken, zwar so, dafs da, wo keine reichliche Sauerstoffentwickelung stattfindet, also in schwach sauren, neutralen und schwach alkalischen Chloridlösungen die sekundäre Chloratbildung im Sinne der Gleichung 1 und 2 vorwiegt, während bei gebotener reichlicher Saverstoffentwickelung, wie sie in stärker alkalischen Lösungen auftritt, die durch die Gleichungen 3 und 4 gekennzeichnete primäre Chloratbildung in den Vordergrund tritt.

Dresden, Anorg.-chemisches Laboratorium der k. sächs. techn. Hochschule.

Bei der Redaktion eingegangen am 8. August 1899. 